\title{
Determinants of Member Participation in Activities of Multipurpose Primary Cooperatives: The Case of Kindo Koysha District, Southern Ethiopia
}

\author{
Hiskeal Hando, ${ }^{1}$ Marisennayya Senapathy $\mathbb{D}^{2},{ }^{2}$ and Elias Bojago $\mathbb{D}^{3}$ \\ ${ }^{1}$ Wolaita Zone, Department of Trade and Market Development, Agricultural Product Marketing and Value Chain Officer, \\ SNNPR, Hawassa, Ethiopia \\ ${ }^{2}$ Department of Rural Development and Agricultural Extension, College of Agriculture, Wolaita Sodo University, \\ Wolaita Sodo, Ethiopia \\ ${ }^{3}$ Department of Environmental Science, College of Natural and Computational Sciences, Wolaita Sodo University, \\ Wolaita Sodo, Ethiopia
}

Correspondence should be addressed to Elias Bojago; eliasboja77@gmail.com

Received 18 October 2021; Revised 13 December 2021; Accepted 23 December 2021; Published 27 January 2022

Academic Editor: Xinqing Xiao

Copyright $\left({ }_{0} 2022\right.$ Hiskeal Hando et al. This is an open access article distributed under the Creative Commons Attribution License, which permits unrestricted use, distribution, and reproduction in any medium, provided the original work is properly cited.

In the modern global economy, members' active participation is critical to the successful implementation of cooperative groups' planned activities. The objectives of this study were to investigate the participation of cooperative members in MPPCs activities and to determine the factors that influence the participation of members in multipurpose cooperatives in the Kindo Koysha district. The study location was chosen for this purpose because no prior in-depth research had been conducted. The multipurpose primary cooperatives were chosen from among the four in the study area based on agro-ecological classifications such as high land, medium land, and low land. The target population of 752 people $(M=594$ and $F=158)$ was chosen using a simple random sample technique with a probability proportional to the size sampling technique (PPS), whereas 106 sample respondents $(M=84$ and $F=22)$ were chosen using (Yamane) implified formula. Primary data were collected using the interview schedule supplied to sample respondents, focus group discussion checklists, and key informant interviews. Secondary data were also collected from several public and unpublished sources. The level of participation in multipurpose cooperatives was measured by computing the participation index score value. The participation of members has been classified as low, medium, or high based on the mean value, which is 40 (37.5\%), $50(47.2 \%)$, and $16(15.1 \%)$, respectively. The ordered logit model was utilized for data analysis, and percentages, mean differences, one-way ANOVA, Spearman correlation, and the chi-square test were performed. According to the findings, education level, family size, total annual income, shareholding amount, access to saving and credit, distance from the cooperative service center, access to and utilization of agricultural inputs, services rendered by MPPCs, perceived challenges of MPPCs that discourage membership, and perceived members satisfaction with cooperative services are the determinant factors that affect the level of membership participation. Continuous education and training, encouraging the issue of family planning, diversification of income-generating schemes, encouraging existing members to buy additional shares, creating the best opportunity for saving and credit, need-based supply of agricultural inputs, resolving the internal and external constraints of multipurpose cooperatives, and strengthening the MPPCs through research-based technical support and follow-up are some of the suggested implications.

\section{Introduction}

1.1. Background of the Study. Cooperatives provide a living for around 300 million people, provide employment for more than 100 million people, cover $25 \%$ of the world's market insurance, and supply $33 \%$ of the world's dairy products. Cooperatives have also demonstrated the important economic contribution of their respective national economies. Compared to Belgium, where cooperative pharmacies have a $19.5 \%$ market share, Brazilian cooperatives are responsible for $40 \%$ of agricultural products and $6 \%$ of overall agribusiness exports in 2007. Cooperatives account 
for $95 \%$ of New Zealand's domestic dairy market and dairy exports [1]. As a result, the cooperative movement is regarded a popular movement in all affluent countries, although in Iran, the government has been the movement's pioneer. This may lead people to mistrust the noble idea of joining cooperatives and to envision them as state or quasi-governmental entities with certain political goals. In such cases, members do not have a sense of belonging to cooperatives and make little effort to fulfill their objectives [2]. According to Kildbary [3], most agricultural cooperatives have failed to achieve long-term success due to the steady deterioration of their members' key roles and the failure to improve management performance in the face of economic changes.

The current cooperative in Ethiopia, on the other hand, was founded in 1969 by Emperor Haile Selassie I. Furthermore, during this time, the first joint legal action was initiated and made public by decree No. 44/1969. The second attempt at cooperative movement occurred in 1972 under the first five-year growth plan. Following the demise of the imperial regime, the transitional military government (Dergue) established a new proclamation regarding cooperative societies. Then, Proclamation No. 138/78 was issued, establishing socialist agriculture and expanding socialist commercial systems in both urban and rural areas. Several cooperative organizations were established throughout the country under this regime. However, they were completely under the control of the government and were unable to pursue their organizational mission and aims independently. After the fall of the Dergue dictatorship in 1991, the EPRDF took control once more. With Proclamation No. 85/1994, the transitional government paved the door for cooperatives in a new form. Furthermore, since 1996, the Ethiopian government has taken significant steps. Among the measures are the consolidation of various cooperative organizations and the establishment of cooperative promotion bureaus and registrars in each region [4]. Cooperation is thus the way of life of Ethiopians, and they have a long history of doing so. Before the advent of contemporary cooperatives, people were organized through traditional cooperatives, which resulted in intimate ties, for example, Idir (for the cause of funereal), Ikub (for the cause of saving money), and Debo (for the cause of labor collaboration during harvest, crop weeding, and house construction). [5]. Farmers can pool their limited resources through cooperatives to reduce risks in agricultural production, which will improve rural socioeconomic development [6].

According to Muthyalu [7], the strength of a cooperative is determined by its ability to mobilize resources while also preserving members' commitment, contentment, and retention. Members who are satisfied and deeply dedicated to their cooperative are more inclined to support it by participating in all MPPC events. As a result, the study was limited to three (3) MPPCs (Hanaze, Sorto, and Bele) chosen from among the four (4) in the study area.

Despite the fact that there are four MPPCs in the study region, one of them (Oydu Chama) was not included in this study owing to time and budget constraints, transportation inaccessibility, including severe topography, and the distance of this MPPC location from the center of the study area. The study's overall objective was to examine the level of members' participation in activities of multipurpose primary cooperatives and also to identify the factors that affect the level of members' participation on MPPCs in the Kindo Koysha district, Wolaita Zone, Ethiopia. In addition, scientific effort has been made to identify the difficulties that require additional investigation and investigation in the research. As a result, other researchers can readily provide potential proposals and solutions to improve members' effective participation and participation in the many activities MPPCs in the study region.

According to Moon [8], the conceptual framework can derive from three interconnected areas: the works of writers and researchers, their personal experience and observations, and the act of reflecting on or interpreting experience and generating research assumptions. As a result, the layout of the conceptual framework, as well as the dependent and independent variables and their relationships, is depicted in Figure 1. Therefore, the main research question of the study is what are the main factors that affect the level of members' participation on MPPCs in the study area?

\section{Materials and Methods}

2.1. Description of the Study Area. The Wolaita Zone is divided into 16 rural districts and six city administrations. The overall population is $2,090,844$, according to the Department of Finance and Economic Development of the Wolaita Zone [9], with 1,030,876 men and 1,060,968 women. The Kindo Koysha district is one of the 16 local Woredas in the SNNPR's Wolayta Zone. It is approximately 410 kilometers southwest of Addis Abeba and approximately 37 kilometers west of Wolaita Sodo. The district comprises 18 local PAs, two small municipalities, and one town (Bele), which is the district's capital. Bloso Sore and Bolso Bombie districts are to the north; Kindo Didaye and Kawo Koysha districts are to the south; Damote Sore, Sodo Zurya, and Bayra Koysha districts are to the east; and the River Omo and Dawro zones are to the west. The district's topography is mountainous and undulating in $90 \%$ of its area, with the other $10 \%$ flat and valley with altitudes ranging from 700 to $1800 \mathrm{~m}$.asl. The district has an area of 89,976 square kilometers and four types of soils: clay, loam, sandy, graves, or stony soils. The study area map is presented in Figure 2.

Due to the rugged topography of the district, it is generally sparsely populated. A larger section of the area is in the lowlands, where livelihoods are jeopardized by high heat and human and cattle diseases. According to the annual report of the Kindo Koysha District Socio-Economic Department Finance and Economic Development Office [11], the district's total population is approximately 137,789 , with males accounting for 66,403 (47.2\%) and females accounting for $71,386(51.8 \%)$. The area faces significant issues due to the volatility of meteorological conditions, which are typically drought, unpredictable rain fall distribution, and other disasters. As a result, Kindo Koysha is classified as a chronic food insecurity district in the Wolaita Zone in the Southern Region. Furthermore, according to people's social lives, the societies are socially linked to each other, with varied ethnic groups, pluralism, and friendliness among the essential 


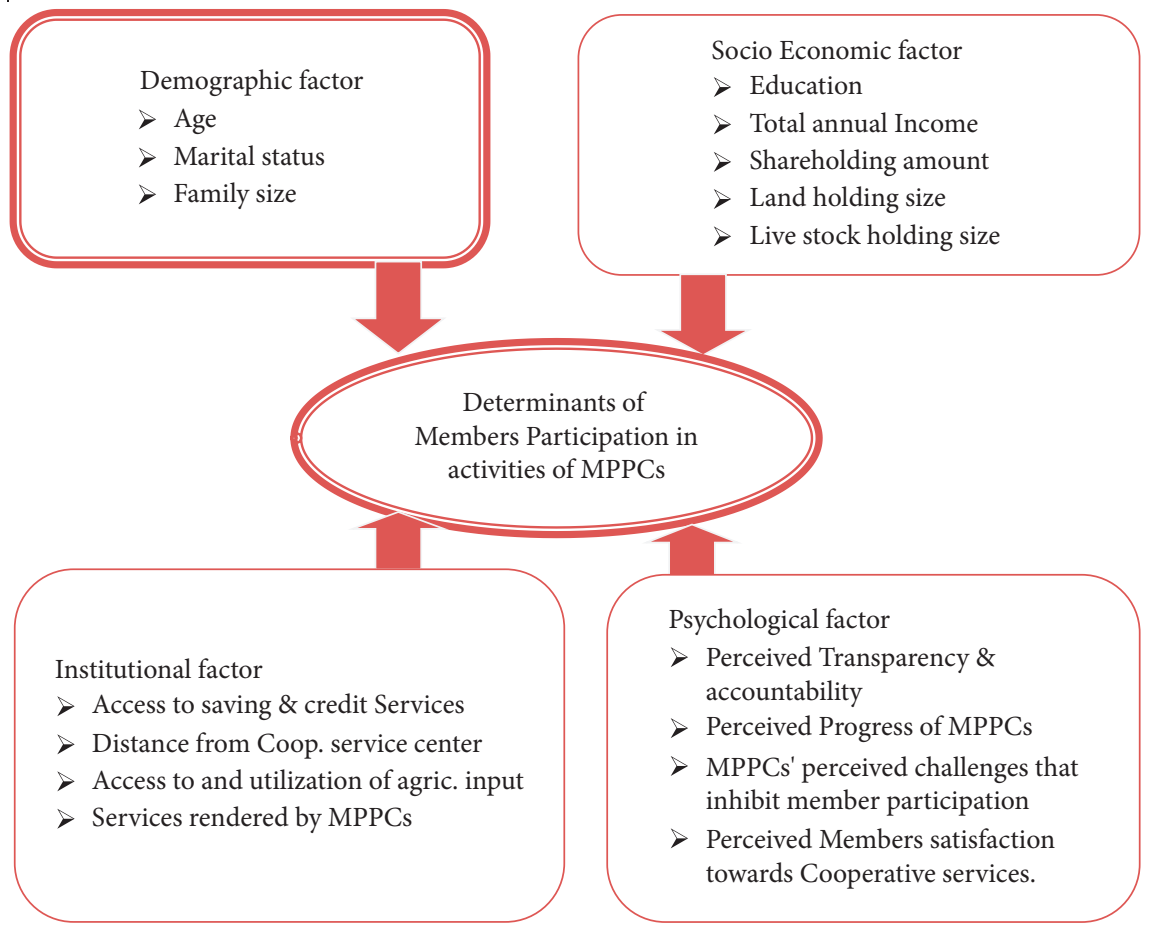

Figure 1: Conceptual framework (source: Own Design Based on the Reviewed Literature (2019)).

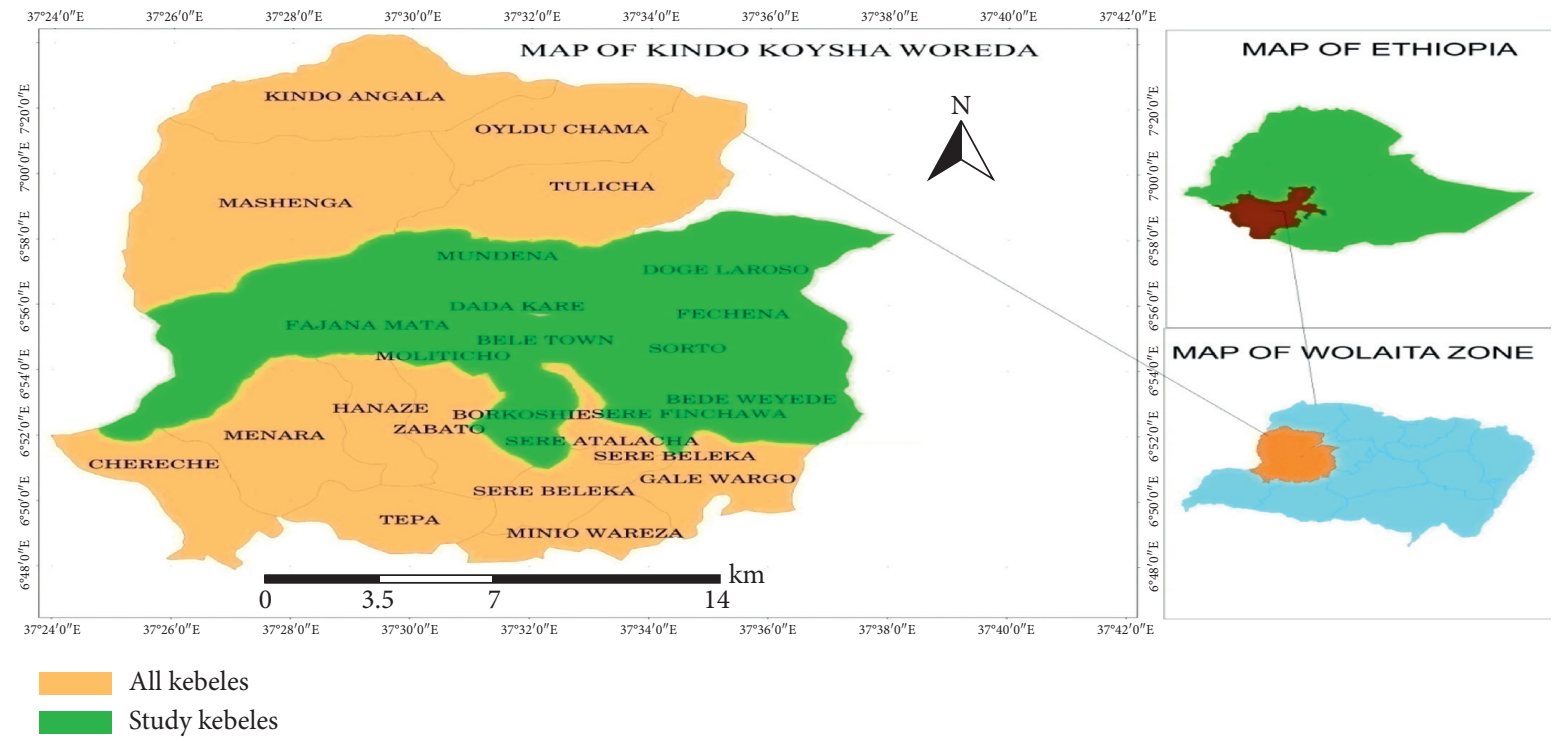

Figure 2: Study area map (source: Finance and Economic Development of Kindo Koysha District [10]).

qualities of the research area's community. Finally, numerous GOs and NGOs, as well as infrastructures such as asphalt (all-weather) roads, electric power, health centers and primary hospitals, and telecom services, are among the accessible social institutions in the research area.

2.2. Research Design. In this research study, the descriptive research design was used. The study's principal foci were based on a description of information connected to member engagement in activities of multipurpose primary cooperatives collected from the study region. As a result, the study employs quantitative and qualitative analysis methodologies to address research issues. Furthermore, descriptive statistics and the ordered logit model (OLM) were used to explain explanatory variables that have a substantial impact on the dependent variable. Finally, all the data obtained were presented and coded before entering them into the Social Sciences Statistical Packages (SPSS) for analysis.

Tables 1 and 2 show multipurpose primary cooperatives and their member and nonmember households in the study 
TABLE 1: Multipurpose primary cooperatives and their member and nonmember households in the study district

\begin{tabular}{lcccccccccc}
\hline \multirow{2}{*}{ Name of MPPCs } & \multirow{2}{*}{ No. of PAs in MPPCs } & \multicolumn{3}{c}{ Total number of HH } & \multicolumn{3}{c}{ Members of MPPCs } & \multicolumn{3}{c}{ Nonmembers of MPPCs } \\
& & Male & Female & Total & Male & Female & Total & Male & Female & Total \\
\hline Oydu Chama & 4 & 2499 & 2563 & 5062 & 196 & 148 & 344 & 2303 & 2415 \\
Sorto & 4 & 2733 & 2843 & 5576 & 223 & 46 & 269 & 2510 & 2797 & 5307 \\
Bele & 6 & 1842 & 1873 & 3715 & 181 & 27 & 208 & 1661 & 1846 & 3507 \\
Hanaze & 4 & 3146 & 3263 & 6409 & 190 & 85 & 275 & 2956 & 3178 & 6134 \\
Total & 18 & 10,220 & 10,542 & 20,762 & 790 & 306 & 1,096 & 9,430 & 10,236 & 19,666 \\
\hline
\end{tabular}

Source: Kindo Koysha District Office of Cooperative Development [12].

TABLE 2: Selected MPPCs and their members in the study area.

\begin{tabular}{lcccc}
\hline & & \multicolumn{3}{c}{$\begin{array}{c}\text { Total size of target } \\
\text { populations }\end{array}$} \\
& 4 & 223 & 46 & 269 \\
Sorto & Male & Female & Total \\
Bele & 6 & 181 & 27 & 208 \\
Hanaze & 4 & 190 & 85 & 275 \\
Total & 14 & 594 & 158 & 752 \\
\hline
\end{tabular}

Source: Kindo Koysha District Office of Cooperative Development [12].

district, as well as selected MPPCs and their members in the study area.

2.2.1. Sample Size Determination. The sample size to collect quantitative and qualitative data for this study was determined using the Yamane [13] formula, which is convenient and simple to use, given as follows:

$$
\begin{aligned}
& n=\frac{N}{1+N e^{2}}, \\
& n=\frac{752}{1+752(0.09)^{2}}, \\
& n=\frac{752}{7.09}=106,
\end{aligned}
$$

where $n$ is the total sample size (106), $N$ is the total target populations from 3 MPPCS (752), and $e^{2}$ is the level of precision, which is $91 \%(0.09)$.

2.2.2. Sampling Procedure. The well-representative sample procedure prepared for this study is represented in Figure 3.

2.3. Methods of Data Collection. The information was gathered from both primary and secondary sources. The goal of combining both strategies was to overcome the limits of each method by obtaining precise data from many sources. The primary source collected some pertinent data through a household survey that included interview with a timetable, checklists for focus group discussions (FGDs), and key informant interviews (KIIs). The secondary source was collected by evaluating and analyzing existing published and unpublished papers on the subject, including the Sectoral Strategic Plan, yearly reports of each selected multifunctional primary cooperative, and the Office of Cooperative Development
(OOCD). The fundamental rationale for relying on primary data is to demonstrate the broad breadth of the idea of multipurpose cooperatives in the study area. As a result, secondary data were intended to supplement the main data.

\subsection{Variable Definitions}

2.4.1. Dependent Variables. The Determinants of Cooperative Members Participation in MPPCs Activities is a dependent variable in this study. Members' participation in multipurpose primary cooperatives is described as the nature and ability of MPPCs members to participate in various MPPC activities. It is calculated on the basis of their participation in various activities. Participation in general meetings, voting and elections, approval and amendments to bylaws, approval of annual planning and budget, participation in evaluating cooperative activities, participation in supplying agricultural products to cooperatives, purchasing agricultural inputs, participation in purchasing additional shares, participation in profit dividend, and participation in $S$ For each indication activity, a score value was assigned, namely Frequently, Rarely, Seldomly, and Never. As a result, the variables were measured and entered into a participation index (PI) generated from several indicators. According to the score values obtained from the participation indicators, the sample respondents were divided into three participation categories and sorted into low, medium, and high.

2.4.2. Independent Variables. After the analytical technique has been clearly defined, the independent factors that may influence member involvement must be identified. It is anticipated that such factors have either positive or negative correlations with the dependent variable. Demographic, socioeconomic, institutional, and psychological aspects are among those considered. Based on the analysis of the researcher's literature, a total of 16 relevant explanatory variables were postulated to explain the study variables (Table 3).

\section{Results and Discussion}

3.1. Participation Indicators of the Sample Respondents. By computing the score values acquired from each responder, the status of the members participating in this study has been determined. After adding up the respondents' responses, the frequency of the indicator activities and the mean value are computed in Table 4. 


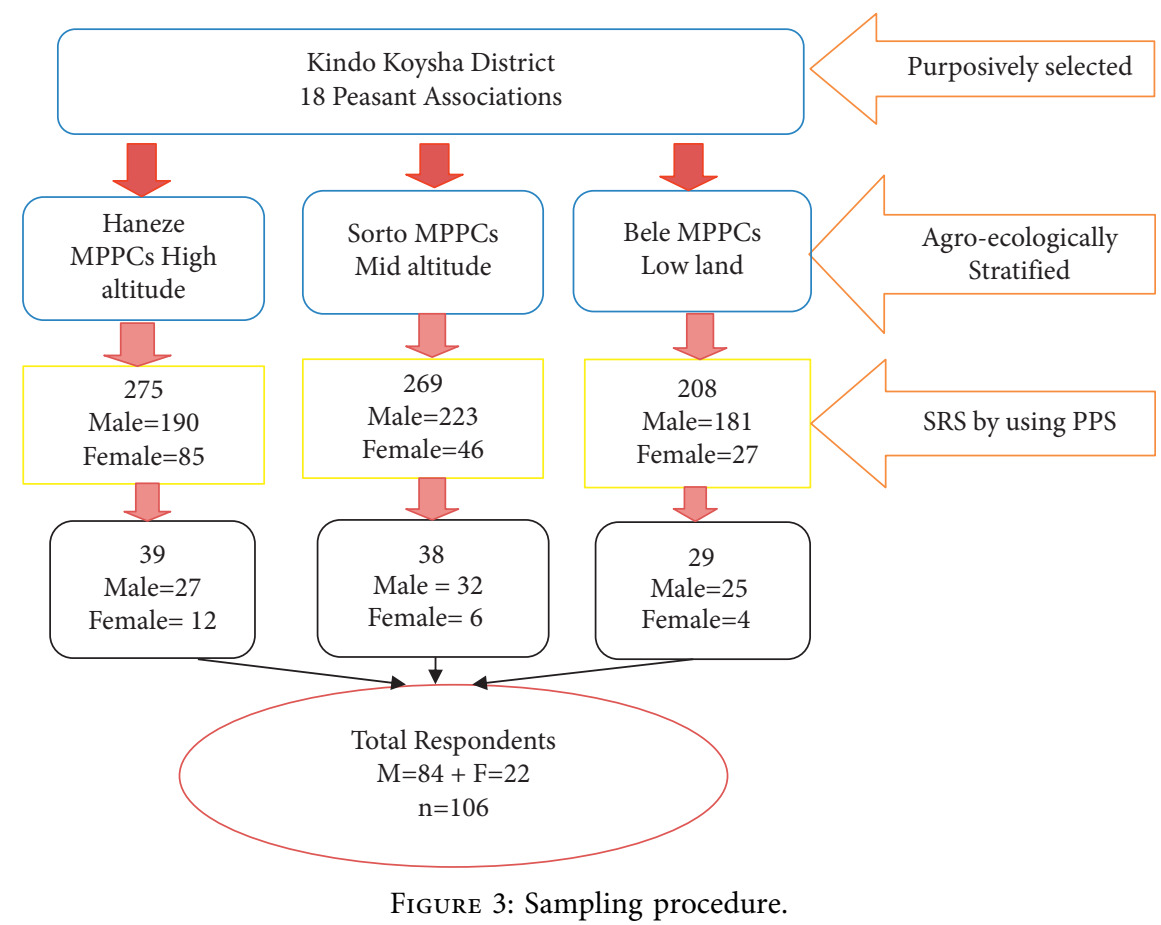

TABLE 3: Summary of hypothesized variables and their expected signs.

\begin{tabular}{|c|c|c|c|c|}
\hline No. & Variable codes & Variable types & Unit of measurements & Expected signs \\
\hline 1 & Age of household (AGHH) & Continuous & Years & $+\mathrm{ve} /-\mathrm{ve}$ \\
\hline 2 & Marital status of household (MSHH) & Categorical & Naming & +ve/-ve \\
\hline 3 & Educational level of household (EDLHH) & Categorical & Naming & +ve \\
\hline 4 & Family size of household (FSHH) & Continuous & Number & $+\mathrm{ve}$ \\
\hline 5 & Total annual income of household (TAIHH) & Continuous & Birr & $+\mathrm{ve}$ \\
\hline 6 & Share hold amount of household (SHHAOH) & Continuous & Amount of share in No. & $+\mathrm{ve}$ \\
\hline 7 & Land holding size of household (LHSHHs) & Continuous & Hectare & + ve \\
\hline 8 & Livestock holding size of HHs (LSHSHHs) & Continuous & TLU & - ve \\
\hline 9 & Access to saving and credit service (ATSC) & Dummy & "1" if yes, " 0 " otherwise & $+\mathrm{ve}$ \\
\hline 10 & Distance from cooperative service (DFCS) & Continuous & Km. & $-\mathrm{ve}$ \\
\hline 11 & Access to and utilization of agricultural inputs (ATUAGI) & Continuous & Quintals & $+\mathrm{ve}$ \\
\hline 12 & Services rendered by MPPC (SRBMPPC) & Categorical & Naming & $+\mathrm{ve}$ \\
\hline 13 & Perceived transparency and accountability (PTAACC) & Dummy & "1" if yes, "0" if no & $-\mathrm{ve}$ \\
\hline 14 & Perceived progress of MPPC (PPOMPPCs) & Dummy & " 1 " if yes, " 0 " if no & $-\mathrm{ve}$ \\
\hline 15 & Perceived challenges of (PCHOMPPCDM) & Dummy & " 1 " if yes, " 0 " if No & +ve \\
\hline 16 & Perceived members satisfaction towards service rendered (PMSTSR) & categorical & Naming & $+\mathrm{ve} /-\mathrm{ve}$ \\
\hline
\end{tabular}

Source: Own Design (2020).

3.2. Methods of Data Analysis. The acquired data were examined using several quantitative and qualitative methodologies that aid in the achievement of the research objectives. To study the concerns that make the research definable, descriptive statistics such as frequency, mean, standard deviation, percentage, and the ordered logit model were used. To determine the validity of the investigation, qualitative data from focus group discussions (FGDs) and key informant interviews (KIIs) were triangulated with quantitative data. The level of participation of cooperative members in MPPC activity was measured by associating the indicator activities with their frequency score values. Respondents were asked to rate their level of participation in ten activities in which they were expected to participate. As a result, the level of participation of cooperative members was determined by their participation as frequently, rarely, rarely, or never. Each response is assigned a value, with sufficient scoring values of $3,2,1$, and 0 . Based on their score values, the participants were divided into three groups: low, medium, and high. As a result, the respondent's score might range from 0 to 318 , with 0 indicating that all members are not engaged in a specific activity, and 318 indicating that all members of cooperatives routinely participate in the aforementioned MPPC activities. As a result, the frequency count of responses was recorded in order to compute the members' participation index (PI) for each selected activity using the following formula: 
TABLE 4: Membership participation and values for indicator activities given.

\begin{tabular}{|c|c|c|}
\hline Categories of Indicators & Nature of participation & Given values \\
\hline \multirow{4}{*}{ Participation in general meeting } & Never & 0 \\
\hline & Seldom & 1 \\
\hline & Rarely & 2 \\
\hline & Frequently & 3 \\
\hline \multirow{4}{*}{ Participation in voting and election } & Never & 0 \\
\hline & Seldom & 1 \\
\hline & Rarely & 2 \\
\hline & Frequently & 3 \\
\hline \multirow{4}{*}{ Participation on approval and amendments bylaw } & Never & 0 \\
\hline & Seldom & 1 \\
\hline & Rarely & 2 \\
\hline & Frequently & 3 \\
\hline \multirow{4}{*}{ Participation in approval of annual planning and budget } & Never & 0 \\
\hline & Seldom & 1 \\
\hline & Rarely & 2 \\
\hline & Frequently & 3 \\
\hline \multirow{4}{*}{ Participation in evaluating cooperative activities } & Never & 0 \\
\hline & Seldom & 1 \\
\hline & Rarely & 2 \\
\hline & Frequently & 3 \\
\hline \multirow{4}{*}{ Participation in supplying agricultural } & Never & 0 \\
\hline & Seldom & 1 \\
\hline & Rarely & 2 \\
\hline & Frequently & 3 \\
\hline \multirow{4}{*}{ Participation in purchasing agricultural inputs } & Never & 0 \\
\hline & Seldom & 1 \\
\hline & Rarely & 2 \\
\hline & Frequently & 3 \\
\hline \multirow{4}{*}{ Participation in buying additional share } & Never & 0 \\
\hline & Seldom & 1 \\
\hline & Rarely & 2 \\
\hline & Frequently & 3 \\
\hline \multirow{4}{*}{ Participation in profit dividend } & Never & 0 \\
\hline & Seldom & 1 \\
\hline & Rarely & 2 \\
\hline & Frequently & 3 \\
\hline \multirow{4}{*}{ Participation in saving and credit } & Never & 0 \\
\hline & Seldom & 1 \\
\hline & Rarely & 2 \\
\hline & Frequently & 3 \\
\hline
\end{tabular}

Source: Own Survey (2020).

$$
\mathrm{PI}=(N 4 \times 3)+(N 3 \times 2)+(N 2 \times 1)+(N 1 \times 0),
$$

where PI is the participation index for different activities in MPPCs, $N 1$ is the number of members who never participate, $N 2$ is the number of members who rarely participate, $N 3$ is the number of members who participate rarely, and N4 represents the number of members who participate frequently in the activities of MPPCs.

To achieve the first objective, we analyze the level of cooperative members' participation in MPPCs in the study areas.

3.2.1. Selection of the Econometric Model. In this study, the ordered logit model (OL) was used due to the ordered or categorical nature of the dependent variable. This model has been widely used to analyze such types of data [14].

3.2.2. Model Specification. Following Green [15] and Liao [14], the functional form of the ordered logit model (OL) is specified as follows:

$$
y^{*}=\sum_{k=1}^{k} \beta_{k}+\varepsilon .
$$

$y^{*}$ is unobserved and thus can be thought of as the underlying tendency of an observed phenomenon. It was assumed that $\varepsilon$ follows a certain symmetric distribution with zero means such as a normal or logistic distribution. What we observe is that 


$$
\begin{array}{ll}
y=1, & \text { If } y^{*} \leq \mu_{1}, \\
y=2, & \text { If } \mu_{1<y^{*}} \leq \mu_{2}, \\
y=3, & \text { If } \mu_{2<y^{*}} \leq \mu_{3} .
\end{array}
$$

$y=j$ if $\mu_{j-1^{*}}<y^{*}$ where $y$ is observed in the $j$-th number of ordered categories and $\mu_{s}$ are unknown threshold parameters that separate the adjacent categories to be estimated with $\beta_{s}$.

The general form of the probability that observed $y$ falls into category $j$ and $\mu_{3}$ and the $\beta_{s}$ are to be estimated with an ordered logit model:

$$
\operatorname{Prob}(y=j)=1-L\left[\mu_{1}-1 \sum_{k=1}^{k} \beta_{k} x\right]
$$

where $L$ represents the cumulative logistic distribution.

3.2.3. Summated Scales (Likert-Type Scales). A total score of 5 points. Using the parameters established by Likert, a Likert scale was used to assess members' attitudes regarding cooperative services [16]. The attitude was measured by the respondents' evaluative perceptions of multipurpose primary cooperative services. The attitude measuring item was completed with the ten most appropriate items, and the item with the highest value was chosen to be included on the scale. The item discriminating index value quantifies how well a set of negative or positive statements distinguish between different levels of groups. After using item analysis to pick the items or sentences, they were incorporated into the scale to measure their attitudes. To determine the attitudes of each respondent, scores were awarded in the following categories: strongly agree (4), agree (3), undecided (2), disagree (1), and strongly disagree (0). In the case of negative (adverse) remarks, the scoring pattern was reversed.

\subsection{The Extent of Membership Participation in Different} Activities of Cooperatives. The frequency with which cooperative members participated in their MPPCs was used to determine their participation in the ten selected activities in Table 5. Respondents were asked how frequently, infrequently, rarely, and never participated in each indicator activity, and the square values for each indicator activity were assigned as 3,2,1, and 0 correspondingly.

As a result, respondents' scores in each participation index for the aforementioned activities range from 0 to 318 , with 0 indicating that no respondents have ever engaged in a particular activity and 318 indicating that all respondents have participated in a given activity frequently. To calculate the participation index, the frequency counts of the respondent's responses were first recorded (PI). Then, using the following formula, the participation index for those distinct activities is calculated. The participation index's computed result is shown in Table 6.

As a consequence, the above result demonstrates that members' participation in activities such as acquiring agricultural inputs, purchasing an extra share, and profit dividend participation is strong, with scored values of
168,160 and 177 , respectively, compared to the expected value of 318. Members' participation in activities such as general meetings, voting and election, supplying agricultural products to cooperatives, and saving and credit is moderate, with score values of $70,71,78$, and 88 , respectively. On the other hand, the membership participation was low on participation in approval and amendments of bylaws, participation in approval of annual planning and budget, and participation in evaluating cooperative activities with a score of 46,49 , and 55 , respectively.

According to Seifu [17] and Hirpo [18], the respondents were divided into three groups based on acquired values: low, medium, and high. This is based on the mean real score of the responses of the respondents for the overall value of the activities. As a result, the respondents were classified into three groups based on their participation scores: 3-8, 9-12, and 13-15 for the low, medium, and high categories, respectively. The score was supposed to range between 0 (the lowest possible score) and 30 (the highest possible score) for each respondent; however, the actual value ranged between 3 and 15. As shown in Figure 4, the aggregate mean of the participating groups was 9.50 . The significance of the mean difference for categories was assessed using one-way ANOVA, and there is a significant mean difference at less than $1 \%$ probability level. As shown in Figure 4, approximately $40(37.7 \%), 50(47.2 \%)$, and $16(15.1 \%)$ of the respondents sampled fall into the low-, medium-, and highlevel participant categories, respectively.

The results from Figure 4 were ensured by the focus group discussion (FGDs) and the key informant interviews (KIIs) held at these three multipurposes during the survey of this study that the level of member's participation is not significant or a small amount of participation in almost all activities of MPPCs. They also confirmed that members' participation in exceptional activities such as purchasing agricultural inputs, purchasing additional shares, and participating in profit dividends is comparatively higher because it is critical and mandatory for their daily life issues. The findings of this study are also similar to those of Mengistu [19] who performed research in the northern Ethiopian region of Amhara.

\subsection{Influence of Independent Variables on Levels of Partici-} pation of Members. The different explanatory variables such as demographic, socioeconomic, and institutional and psychological factors were analyzed to test whether they have a significant/positive or insignificant/negative impact on the dependent variable.

\subsubsection{Demographic Factors}

(1) Age of the Respondents. The study's objective was to describe the ages of the respondents who had participated in various cooperative activities. This variable was expected to have an impact on the study's dependent variables, either positively or negatively. As shown in Table 7, Spearman correlations $(r=0.308)$ show a positive and strong 
TABLE 5: Frequency of membership participation in activities of multipurpose cooperatives.

\begin{tabular}{|c|c|c|c|c|c|c|c|c|c|c|}
\hline \multirow{2}{*}{ Types of indicators } & \multicolumn{2}{|c|}{ Frequently } & \multicolumn{2}{|c|}{ Rarely } & \multicolumn{2}{|c|}{ Seldom } & \multicolumn{2}{|c|}{ Never } & \multicolumn{2}{|c|}{ Total } \\
\hline & $N$ & $\%$ & $N$ & $\%$ & $N$ & $\%$ & $N$ & $\%$ & $N$ & $\%$ \\
\hline Participation on general meeting & 9 & 8.5 & 6 & 5.7 & 31 & 29.2 & 60 & 56.6 & 106 & 100 \\
\hline Participation on voting and election & 6 & 5.6 & 13 & 12.3 & 27 & 25.5 & 60 & 56.6 & 106 & 100 \\
\hline Participation in approval and amendments of bylaws & 0 & 0 & 10 & 9.4 & 26 & 24.5 & 70 & 66 & 106 & 100 \\
\hline Participation in approval of annual planning and budget & 0 & 0 & 8 & 7.6 & 33 & 31.1 & 65 & 61.3 & 106 & 100 \\
\hline Participation on evaluating cooperative activities & 5 & 4.7 & 11 & 10.4 & 18 & 17 & 72 & 67.9 & 106 & 100 \\
\hline Participation on supplying agricultural products & 8 & 7.5 & 24 & 22.6 & 6 & 5.7 & 68 & 64.2 & 106 & 100 \\
\hline Participation on purchasing agricultural inputs & 36 & 34 & 22 & 20.8 & 16 & 15 & 32 & 30.2 & 106 & 100 \\
\hline Participation in buying additional share & 40 & 37.7 & 16 & 15.2 & 8 & 7.5 & 42 & 39.6 & 106 & 100 \\
\hline Participation on profit dividend & 30 & 20.3 & 35 & 33 & 17 & 16 & 24 & 22.6 & 106 & 100 \\
\hline Participation in saving and credit & 12 & 11.3 & 19 & 18 & 14 & 13.2 & 61 & 57.5 & 106 & 100 \\
\hline
\end{tabular}

Table 6: Participation index and score values.

\begin{tabular}{|c|c|c|c|c|}
\hline \multirow{2}{*}{$\begin{array}{l}\text { Indicators } \\
\text { Participation on general meeting }\end{array}$} & \multicolumn{4}{|c|}{ Score values } \\
\hline & $\mathrm{PI}=(9 \times 3)+$ & $(6 \times 2)+$ & $(31 \times 1)+$ & $(60 \times 0)=70$ \\
\hline Participation on voting and election & $P I=(6 \times 3)+$ & $(13 \times 2)+$ & $(27 \times 1)+$ & $(60 \times 0)=71$ \\
\hline Participation on approval and amendments of bylaws & $\mathrm{PI}=(0 \times 3)+$ & $(10 \times 2)+$ & $(26 \times 1)+$ & $(70 \times 0)=46$ \\
\hline Participation on approval of the annual planning and budget & $\mathrm{PI}=(0 \times 3)+$ & $(8 \times 2)+$ & $(33 \times 1)+$ & $(65 \times 0)=49$ \\
\hline Participation evaluating cooperative activities & $\mathrm{PI}=(5 \times 3)+$ & $(11 \times 2)+$ & $(18 \times 1)+$ & $(72 \times 0)=55$ \\
\hline Participation on supplying agricultural products & $\mathrm{PI}=(8 \times 3)+$ & $(24 \times 2)+$ & $(6 \times 1)+$ & $(68 \times 0)=78$ \\
\hline Participation on purchasing agricultural inputs & $\mathrm{PI}=(36 \times 3+$ & $(22 \times 2)+$ & $(16 \times 1)+$ & $(32 \times 0)=168$ \\
\hline Participation on buying additional share & $\mathrm{PI}=(40 \times 3+$ & $(16 \times 2)+$ & $(8 \times 1)+$ & $(42 \times 0)=160$ \\
\hline Participation on profit dividend & $\mathrm{PI}=(30 \times 3+$ & $(35 \times 2)+$ & $(17 \times 1)+$ & $(24 \times 0)=177$ \\
\hline Participation on saving and credit & $\mathrm{PI}=(12 \times 3+$ & $(19 \times 2)+$ & $(14 \times 1)+$ & $(61 \times 0)=88$ \\
\hline
\end{tabular}

Note: $(\mathrm{PI})=(N 4 \times 3)+(N 3 \times 2)+(N 2 \times 1)+(N 1 \times 0)$ (source: Own Survey $(2020))$.

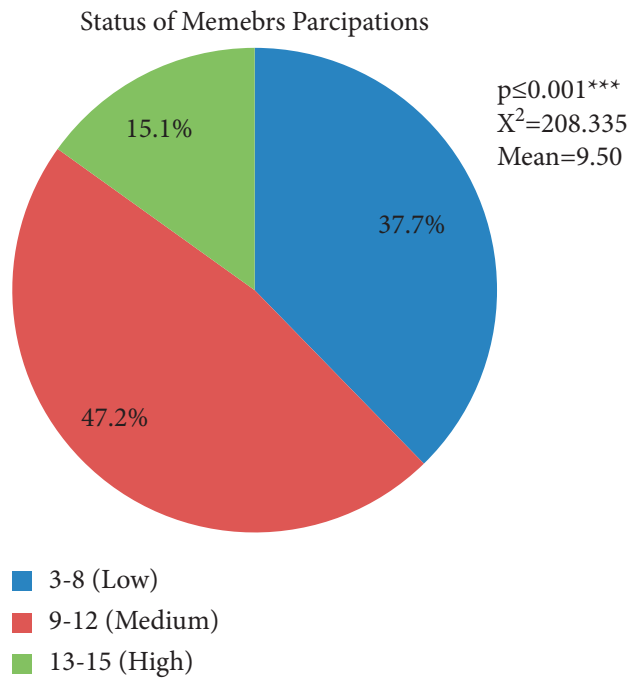

Figure 4: Participation statuses and their score ranges (source: Own survey (2020)).

relationship between respondents' age and level of participation in cooperative activities.

The one-way ANOVA test $(F=5.555, P=0.005)$ reveals that there is a significant mean difference between the ages of the respondents in the different participant categories and that this has a positive influence on the level of participation of the members in different cooperative activities. Previous research such as $[20,21]$ found that the age of the household head has a positive and significant relationship with cooperative membership, whereas [22-24] confirmed that age has a nonlinear effect.

(2) Family Size. The family size of the household is an essential factor in expressing the participation of members in cooperative activities. It was predicted that there would be a significant relationship between it and the dependent variable. According to Table 7, the average family size of the respondents in the low, medium, and high categories is 2.90 , 3.24 , and 3.44 , respectively. The Spearman correlation coefficient $(r=0.212)$ describes a positive relationship between family size and cooperative membership. On the other hand, the results of the one-way ANOVA test $(F=2.508$ and $P=0.086)$ show that the mean difference in family size between the participatory categories has a significant relationship with the dependent variable. Previous research has found that family size is another factor that influences membership decisions positively $[21,25]$.

(3) Marital Status of Households. The marital status of the respondents describes the positive and negative participation of the members in cooperative activities. The chi-square test was revealed by the results in Table $7\left(x^{2}=0.816\right.$ and $P=0.378$ ). As a result, the results show that there is no significant relationship between members' participation and the marital status of the respective respondents' married, single, divorced, or widowed households. 
TABLE 7: Relationship between demographic factors and levels of participation of members.

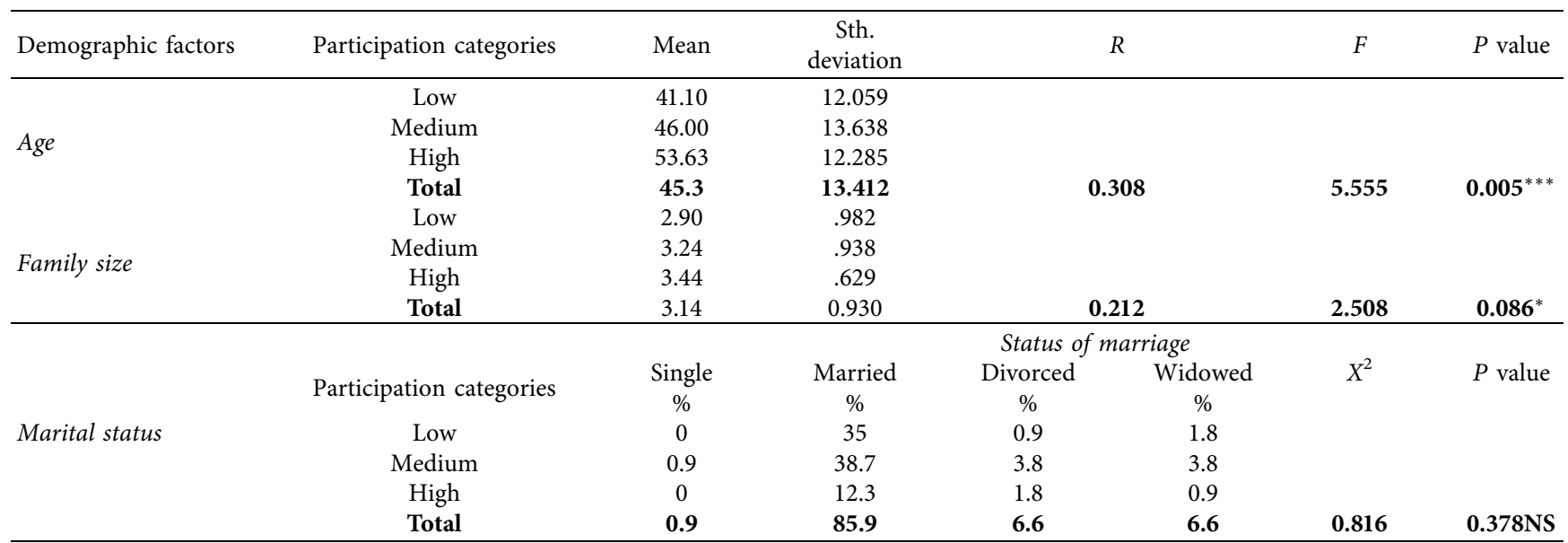

${ }^{*}$ Significant at the $10 \%$ probability level, ${ }^{* * *}$ significant at $1 \%$ probability level, and NS: not significant (source: Own Survey, 2020).

\subsubsection{Socioeconomic Factors}

(1) Total Annual Income. Income is the total amount of money or capital earned by members each year from various sources. The results in Table 8 show that ETB 9664.93, ETB 13524.30, and ETB 21120.62 are the prices for the low, medium, and high participant categories, respectively. The Spearman correlation coefficient $(r=0.360)$ shows a positive relationship between the income of the respondents and the dependent variable. The one-way ANOVA $(F=8.188$ and $P=0.001$ ) reveals a significant mean difference at a $1 \%$ probability level in the income of the cooperatives' different income categories.

(2) Shareholding Amount of Households. This variable refers to the amount of paid-up share capital owned by the members; it was expected that the more the members held the share considered, the more they participated and benefited from the cooperative's business activities. As shown in Table 8, the Spearman correlation $(r=0.328)$ demonstrates an appositive relationship between the shareholding amount of the members and their level of participation in cooperative activities. The one-way ANOVA value $(F=6.212$ and $P=0.003)$ also revealed that there is a significant mean difference at the $1 \%$ level between the shareholding amount and the participation of members in cooperative activities.

(3) Land Holding Size. This refers to the total farm land owned by the respondents, measured in hectares. As a result, it was hypothesized that land holding size has a positive relationship and can influence members' participation in cooperative activities. As shown in Table 8, the total mean land holding size of those in the low, medium, and high participant groups is $1.78,1.93$, and 2.25 hectares, with an average standard deviation of $0.725,1.165$, and 1.1342 , respectively. The Spearman correlation $(r=0.144)$ shows a positive relationship between the average size of the land holding and the participation of the members. The result of one-way ANOVA $(F=1.168$ and $P=0.315)$ shows no significant mean difference between land holding size, and members participate in the cooperative activities. The size of the land holding has a positive and statistically significant effect on the likelihood of membership. This is acceptable because larger farms are not only wealthier, but also have a greater capacity to develop agricultural production, which drives farmers to form cooperatives in order to sell their produce and conveniently acquire farm input. The findings are congruent with those of Thorp et al. [26] and Francesconi and Heerinck [27], who discovered that agricultural cooperatives exclude the poorest farmers. Ito et al. [22] also demonstrated that smallholder farmers will self-exclude from agricultural cooperatives if the costs of membership outweigh the benefits of membership.

(4) Livestock Holding Size. Livestock is an important source of income and draught power for farmers and is measured in Tropical Livestock Unit (TLU). As shown in Table 8, it is reasonable to expect that the increase in the value of livestock units has increased participation in multipurpose primary cooperatives. The Spearman correlation $(r=-0.013)$ reveals a weak and negative relationship between the size of the livestock holding and the participation in cooperative activities between the members. The one-way ANOVA $(F=0.081$ and $P=0.922)$ also reveals no significant mean difference between the size of the livestock holding of different groups of participants category. Earlier research found that farmers' asset ownership matters when it comes to joining cooperatives. The size of owned land and livestock holdings, for example, are proven to have a beneficial effect on cooperative membership [23, 25,27]. In contrast, Verhofstadt and Maertens [28] found that having more land reduces the likelihood of being a cooperative member, whereas others (such as [21,22]) found that both the poorest and wealthiest farmers are the least likely to participate in agricultural cooperatives.

(5) Education Level of Households. It was expected that the education level of the respondents would influence the participation of the members in cooperative activities 


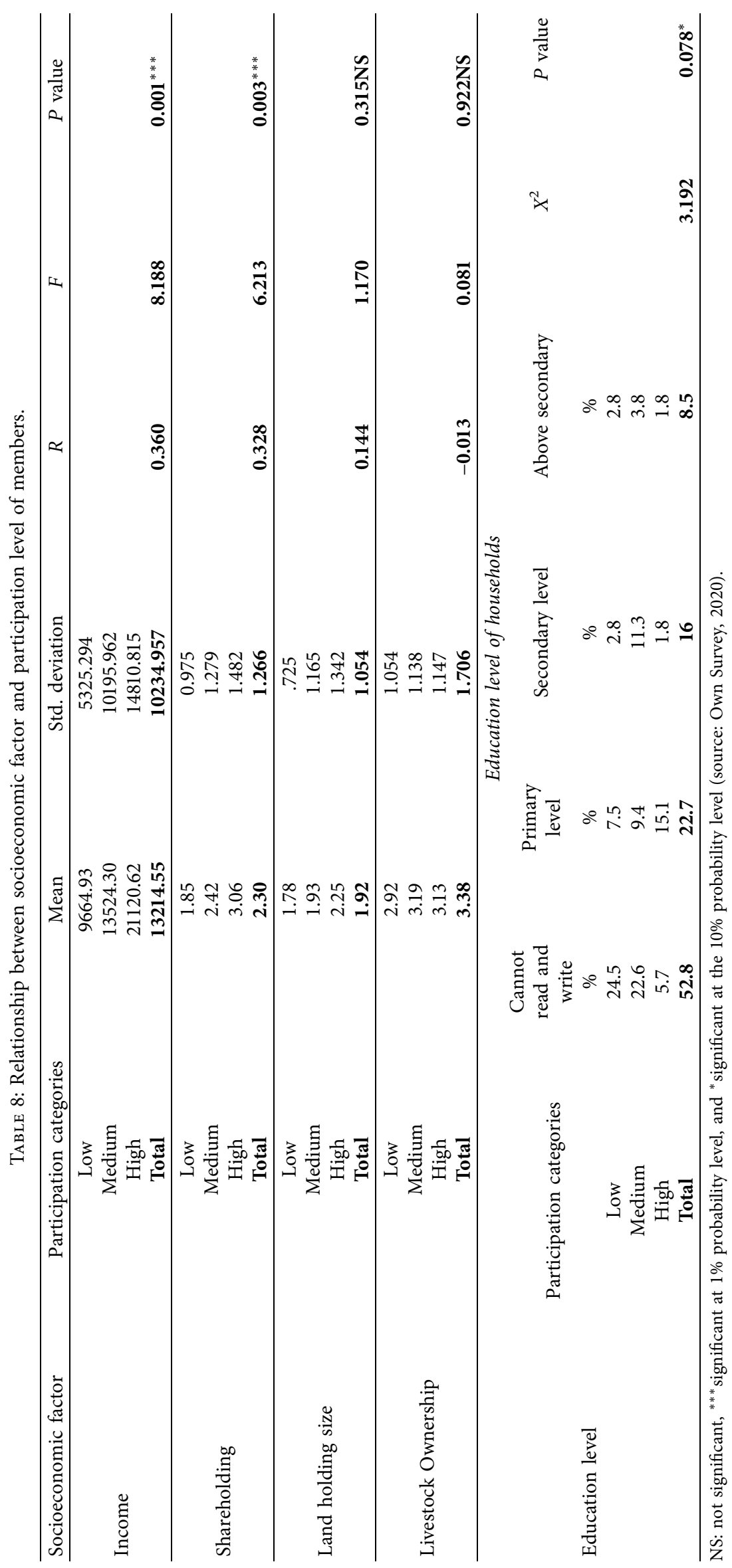




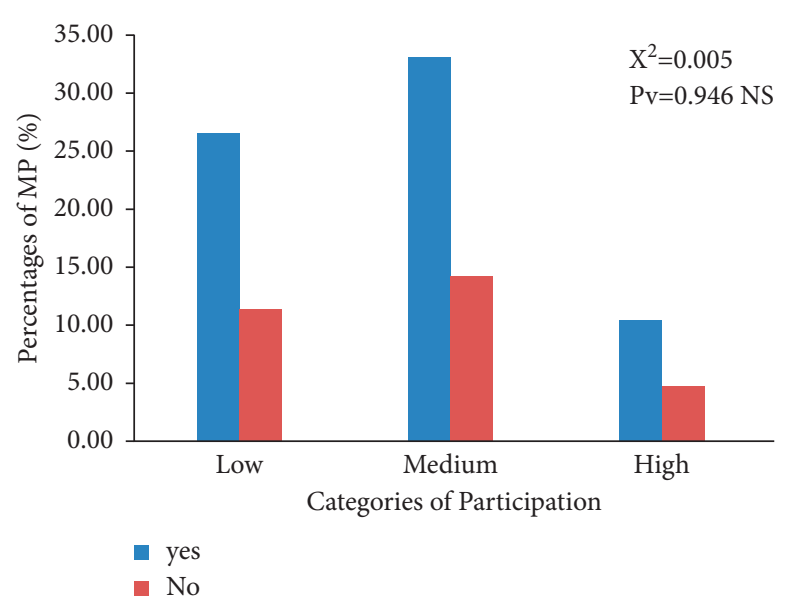

FIGURE 5: Relationship between saving and credit accessibility and member participation. Note: NS = not significant (source: Own survey (2020).

because educated members are more aware of their duties and responsibilities and enjoy democratic rights than uneducated members. As shown in Table 8, the findings of this study $\left(x^{2}=3.192\right.$ and $\left.P=0.078^{*}\right)$ revealed a significant relationship at a probability level of $10 \%$ between the level of education and the participation of the members in various cooperative activities. Another personal characteristic that can favorably influence cooperative participation is the household head's educational degree $[21,25,28]$.

\subsubsection{Institutional Factors}

(1) Access to Credit and Saving Service. Credit and saving institution accessibility is critical in increasing the use of input/output service enrolment and is expected to positively influence members' intensity of participation in cooperative organizations SIDA [29]. The analysis in Figure 5 revealed that $74(69.8 \%)$ responded that credit service is available. However, approximately $32(30.2 \%)$ of those polled stated that credit is more difficult to obtain in the area. The chisquare test $\left(x^{2}=0.005\right.$ and $\left.P=0.946\right)$ reveals no statistically significant relationship between member credit accessibility and the dependent variable.

(2) Distance from Cooperative Services. It refers to the proximity of the cooperatives from the members' residence that reduce the cost of time and labor that the farmers spent to achieve various types of services from their cooperatives. This study was expected to find a significant effect with this variable on the level of participation of the members in various cooperative activities, as the findings show that the mean difference for the low, medium, and high participant groups is $1.68,1.62$, and $1.31 \mathrm{~km}$, respectively. The Spearman correlation $(r=-0.165)$ demonstrates a negative relationship between member participation and the distance traveled to their cooperatives. As shown in Table 9, the one-way ANOVA $(F=1.918$ and $0.152 \mathrm{NS})$ indicates that there is no significant mean difference between the participation groups Table 9.
(3) Access to and Utilization of Agricultural Inputs. It refers to members' ability and access to purchase a certain amount of agricultural input. It was expected to have a positive impact on members' participation in various cooperative activities. The access and average agricultural input utilization rates of the low, medium, and high response category groups are 1.92, 2.14, and 3.02, respectively, as shown in Table 9. The Spearman correlation $(r=0.200)$ reveals a positive and significant relationship between access to and utilization of agricultural inputs and the level of membership participation in the issues. On the other hand, one-way ANOVA $(F=2.659$ and $P=0.775)$ indicates significant mean differences in the use of agricultural inputs among the different groups of participants at a probability level of $10 \%$.

(4) Services Rendered by Multipurpose Primary Cooperatives. It refers to the capacity of multipurpose primary cooperatives to address and provide the planned activities and services to their members. As shown in Table 9, approximately $13(11.3 \%), 12(11.3 \%), 38(37.5 \%)$, and $43(40.6 \%)$ of respondents rated their multipurpose primary cooperatives' services and activities as very good, good, satisfactory, and poor, respectively. The chi-square test $\left(x^{2}=5.310\right.$ and $P=0.025)$ indicates a positive and significant relationship at a probability level of $5 \%$ between the services provided by MPPCs and the level of members participating in various cooperative activities.

\subsubsection{Psychological Factors}

(1) Perceived Transparency and Accountability. It refers to the transparency and accountability of the board of directors (BODs), managers, and recruited employees in their cooperatives for every activity and duty. The willingness and ability of the board of directors and employees to conduct and execute the planned activities and services in a transparent and accountable manner for the benefit and development of cooperative associations and their members are important indicators of these issues. It was anticipated that there would 


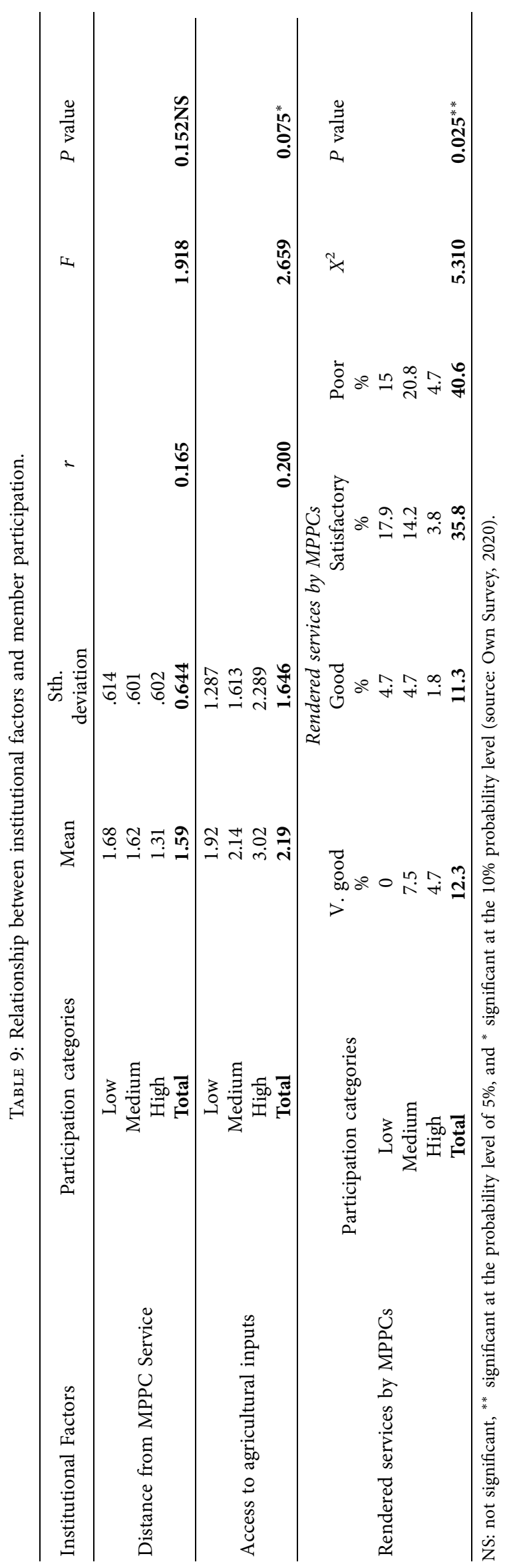


TABLE 10: Relationship between psychological factors and accountability.

\begin{tabular}{|c|c|c|c|c|c|c|c|}
\hline \multirow{2}{*}{ Psychological factors } & \multirow{2}{*}{ Categories of participation } & \multicolumn{2}{|c|}{ Yes } & \multicolumn{2}{|c|}{ No } & \multirow{2}{*}{$x^{2}$} & \multirow{2}{*}{$P$ value } \\
\hline & & No & $\%$ & No & $\%$ & & \\
\hline \multirow{4}{*}{ Perceived transparency } & Low & 19 & 18 & 21 & 19.8 & & \\
\hline & Medium & 28 & 26.4 & 22 & 20.7 & & \\
\hline & High & 12 & 11.3 & 4 & 3.8 & & \\
\hline & Total & 59 & 55.7 & 47 & 44.3 & 3.034 & $0.084^{*}$ \\
\hline \multirow{4}{*}{ Perceived progress } & Low & 9 & 8.5 & 30 & 28.3 & & \\
\hline & Medium & 16 & 15 & 34 & 32 & & \\
\hline & High & 8 & 7.5 & 8 & 7.5 & & \\
\hline & Total & 33 & 31.1 & 73 & 68.9 & 3.734 & $0.054^{*}$ \\
\hline \multirow{4}{*}{ Perceived challenges } & Low & 20 & 18.7 & 20 & 18.7 & & \\
\hline & Medium & 35 & 33 & 15 & 14.2 & & \\
\hline & High & 10 & 9.4 & 6 & 5.7 & & \\
\hline & Total & 65 & 61.3 & 41 & 38.7 & 2.294 & $0.129 N S$ \\
\hline \multirow{6}{*}{ Perceived satisfaction } & & \multicolumn{6}{|c|}{ Perceived member satisfaction } \\
\hline & Categories or participation & Mean & Std. devia & & $r$ & $F$ & $P$ value \\
\hline & Low & 2.73 & 1.211 & & & & \\
\hline & Medium & 3.18 & 1.175 & & & & \\
\hline & High & 3.63 & 1.316 & & & & \\
\hline & Total & 3.08 & 1.238 & & 0.252 & 3.489 & $\mathbf{0 . 0 3 4 ^ { * * }}$ \\
\hline
\end{tabular}

${ }^{* *}$ Significant at the probability level of $5 \%,{ }^{*}$ significant at the $10 \%$ probability level, and NS: not significant (source: Own Survey, 2020).

be a negative or significant relationship between member participation in cooperative activities. As a result, the study findings in Table 10 show that approximately 59 (55.7\%) of the respondents stated that there is no problem with transparency and accountability in the general activities and services of the board of directors, managers, and other employees in carrying out their duties and responsibilities. On the other hand, approximately $59(55.7 \%)$ of the respondents thought there was good transparency and accountability. Approximately 47 (44.3\%) of the respondents perceived transparency and accountability limits in the overall activities and services of multipurpose primary cooperatives. The result of the chisquare test $\left(x^{2}=3.034\right.$ and $\left.P=0.084\right)$ also shows a positive and significant relationship between perceived transparency and accountability of cooperatives and the level of participation of members at $10 \%$ of the probability level.

(2) Perceived Progress of Multipurpose Primary Cooperatives. It refers to how members perceive the progress of the cooperative. It was intended to investigate issues concerning members' reflections on cooperatives, improved progress in the total amount of capital, improved progress in addressing relevant services, improved participation of members in various cooperative activities, and so on. It was expected to have a positive or significant relationship with the level of participation of members in cooperative activities. According to the results of the study (Table 10), about $33(31.1 \%)$ of respondents saw substantial progress in their multipurpose primary cooperatives, whereas approximately $73(68.9 \%)$ of the sampled respondents stated that they did not see any significant progress in their multipurpose primary cooperatives. As shown in Table 10, at a $10 \%$ probability level, the chisquare test $\left(x^{2}=3.737\right.$ and $\left.P=0.054\right)$ indicates a significant relationship between the perceived progress of cooperatives and the level of participation of members. The focus group discussion (FGD) also confirmed that multipurpose primary cooperatives have made no significant progress on multidimensional issues and that they cannot afford to meet and address the needs of their members.

(3) Perceived Challenges of Cooperatives that Dissuade Members' Participation. It refers to challenges that discourage members from participating in the various activities of cooperatives. According to the data analysis findings in Table 10, approximately $65(61.3 \%)$ of the sample respondents stated that cooperatives in the study area faced a variety of economic, social, and political issues that had a significant impact on member participation, whereas approximately $41(37.5 \%)$ of the respondents reiterated that they had not perceived any challenges that discouraged membership participation. The chi-square test $\left(x^{2}=2.214\right.$ and $P=0.129(\mathrm{NS})$ ) reveals no significant relationship between perceived challenges and cooperative membership.

(4) Perceived Member Satisfaction with Service Rendered. It refers to the satisfaction of members with the various services provided by multipurpose primary cooperatives. It was evaluated in terms of their evaluative perceptions using the scale values developed for this study. The weighted average of the score for positive statements. Perception was assigned a score of $5,4,3,2$, and 1 for strongly agree, agree, undecided, disagree, and strongly disagree. For negative statements, the score value was reversed and assigned to strongly disagree, disagree, undecided, agree, and strongly agree, respectively. Members' perceived satisfaction was measured using the summated rating scale, which ranges from 1 to $1.80,1.81$ to $2.60,2.61$ to $3.40,3.41$ to 4.20 , and 4.21 to 5.00 for strongly disagree, disagree, undecided, agree, and strongly agree, respectively. As a result, the reverse rating scale is correct for positive statements. The mean value for participants in the low, medium, and high categories 
TABLE 11: Variance inflation factor for continuous variable.

\begin{tabular}{lccc}
\hline No. & Variables & Tolerance & VIF \\
\hline 1 & AGE & 0.621 & 1.610 \\
2 & FSHH & 0.711 & 1.407 \\
3 & TAI & 0.474 & 1.110 \\
4 & SHHA & 0.736 & 1.358 \\
5 & LHS & 0.569 & 1.756 \\
6 & LSHS & 0.810 & 1.235 \\
7 & DFCS & 0.948 & 1.055 \\
8 & ATUAGI & 0.449 & 1.228 \\
9 & PMSTCS & 0.839 & 1.193 \\
\hline
\end{tabular}

Source: Model Output (2020)

was $2.73,3.18$, and 3.63 , respectively. The results below show that the respondents have different perception levels that can affect their participation in different cooperative activities. As shown in Table 10, the mean value of 3.63 for the high participant category indicates that respondents with positive or constructive perceptions were more likely to be enrolled than those with medium or low scores. The Spearman correlation (r.252) indicates a positive and significant relationship between member participation and satisfaction with cooperative service. According to the statistical analysis obtained from one-way ANOVA $(F=3.489$ and $P=0.034)$, there are significant mean differences at the $5 \%$ probability level between the perception level of the respondents and their level of participation in MPPC activities (Table 10).

\subsection{Summary of the Hypothesized Explanatory Variables}

3.5.1. Hypothesized Continuous Variables. Table 11 summarizes the study findings obtained by descriptive and inferential statistical analysis. Using data from the study area, the most important factors that were hypothesized to have a significant impact on members' level of participation in multipurpose primary cooperatives were analyzed. A total of 16 independent variables were hypothesized and tested to determine whether they had a significant influence on the dependent variable. Nine of the 16 independent variables are continuous, whereas the remaining seven are dummy/discrete variables. As a result, the continuous variables and their relationships with the dependent variables are indicated in Table 12.

As shown in Table 11, three of the nine continuous variables are significant at the $1 \%$ probability level: age, total annual income, and shareholding amount of households; one is significant at the $5 \%$ probability level: perceived members satisfaction with cooperative service; and two are significant at the $10 \%$ probability level: access to and use of agricultural inputs and family size. At the same time, the other three variables, the size of the household land holding, the size of the livestock holding, and the distance from the cooperative service, are not significantly related to the dependent variable.

3.5.2. Hypothesized Dummy Variables. This section provides a brief summary of the findings of dummy variables obtained by inferential statistics. For this study, approximately 7 important dummy variables that are expected to have a significant impact on the participation of cooperative members were used. According to the findings in Table 13, one of them, cooperative services, is significant at a $5 \%$ probability level, and three others, household education level, perceived transparency and accountability, and perceived progress of cooperatives, are significant at a probability level of $10 \%$. On the other hand, 3 factors, marital status of the household, access to and utilization of saving and credit services, and perceived challenges, do not significantly influence the dependent variable..

3.6. Result of the Ordered Logit Regression Model. The multicollinearity test has been performed for all continuous and dummy explanatory variables to measure the existence of the multicollinearity problem.

To see the multicollinearity problem among the dummy variables, the contingency coefficient (CC) was used. The contingency coefficient ranges from 0 to 1 , with 0 indicating that there is no association between the variables. If the value is close to one, it indicates that the variables are highly associated. If the value of the contingency coefficient exceeds 0.78 , the association is said to be strong. As a result, based on the criteria provided, there is no multicollinearity problem among the dummy variables (see Table 14). The variance inflation factor (VIF), on the other hand, was used to test a multicollinearity problem among continuous variables (Table 14). The VIF demonstrates that the presence of a multicollinearity problem inflates an estimator's variance [30]. As a result, none of the values exceed the ranges, and there is no multicollinearity problem among the continuous variables, according to the results of the test in Table 11.

\subsection{Summary of Quantitatively Significant Explanatory} Variables. The ordered logit regression model was used to incorporate the various independent variables that were hypothesized to have a significant impact on the dependent variable.

According to the results of the study in Table 15, the majority have a significant effect on the dependent variable. Therefore, the variables that have a significant impact on the dependent variable are the following: the family size of the household $(\mathrm{FSHH})$, total annual income of the household (TAIHH), shareholding amount of the household (SHHAHH), distance from cooperative service (DFCS), 
TABLE 12: Summary of continuous variables and relationship between member participation.

\begin{tabular}{|c|c|c|c|c|c|c|c|c|}
\hline \multirow{2}{*}{ Variables } & \multicolumn{8}{|c|}{ Mean of the participation category } \\
\hline & Low & Medium & High & Mean & Std. deviation & $R$ & $F$ & $P$ \\
\hline AGHH & 41.1 & 46 & 53.63 & 45.3 & 13.412 & 0.308 & 2.915 & $0.005^{* * *}$ \\
\hline FSHH & 2.9 & 3.24 & 3.44 & 3.14 & 0.934 & 0.212 & 2.508 & $0.086^{*}$ \\
\hline TAIHH & 9664.93 & 13524.3 & 21120.62 & 13214.55 & 10234.96 & 0.36 & 8.188 & $0.001^{* * *}$ \\
\hline SHHAHH & 1.85 & 2.42 & 3.06 & 2.3 & 1.266 & 0.328 & 6.213 & $0.003^{* * *}$ \\
\hline LHSHH & 1.78 & 1.93 & 2.25 & 1.92 & 1.054 & 0.144 & 1.17 & $0.315 \mathrm{NS}$ \\
\hline LSHSHH & 2.92 & 3.19 & 3.13 & 3.38 & 1.706 & 0.013 & 0.081 & $0.922 \mathrm{NS}$ \\
\hline DFCS & 1.68 & 1.62 & 1.33 & 1.59 & 0.644 & 0.165 & 1.918 & $0.152 \mathrm{NS}$ \\
\hline ATUAGI & 1.92 & 2.14 & 3.02 & 2.19 & 1.646 & 0.2 & 2.689 & $0.075^{*}$ \\
\hline PMSTCS & 2.73 & 3.18 & 3.63 & 3.08 & 1.238 & 0.252 & 3.489 & $0.034^{* *}$ \\
\hline
\end{tabular}

${ }^{*},{ }^{* *}$, and ${ }^{* * *}$ : Significant at $10 \%, 5 \%$, and $1 \%$, respectively. NS: not significant (source: Own survey, 2020).

TABLE 13: Summary of the relationship between dummy variables and member participation.

\begin{tabular}{|c|c|c|c|c|c|c|c|c|c|}
\hline \multirow{3}{*}{ Variables } & \multicolumn{9}{|c|}{ Participation category } \\
\hline & \multirow[t]{2}{*}{ Description } & \multicolumn{2}{|c|}{ Low } & \multicolumn{2}{|c|}{ Medium } & \multicolumn{2}{|c|}{ High } & \multirow[t]{2}{*}{$X^{2}$} & \multirow[t]{2}{*}{$P$} \\
\hline & & $N$ & $\%$ & $N$ & $\%$ & $N$ & $\%$ & & \\
\hline \multirow{4}{*}{ MSHH } & Single & 0 & 0 & 1 & 0.9 & 0 & 0 & 0.816 & $0.378 \mathrm{NS}$ \\
\hline & Married & 37 & 35 & 41 & 38.7 & 13 & 12.3 & & \\
\hline & Divorced & 1 & 0.9 & 4 & 3.8 & 2 & 1.8 & & \\
\hline & Widowed & 2 & 1.8 & 4 & 3.8 & 1 & 0.9 & & \\
\hline \multirow{4}{*}{ EDLHH } & Cannot read and write & 26 & 24.5 & 24 & 22.6 & 6 & 5.7 & 3.192 & $0.078^{*}$ \\
\hline & Primary level & 8 & 7.5 & 10 & 9.4 & 16 & 15.1 & & \\
\hline & Secondary level & 3 & 2.8 & 12 & 11.3 & 2 & 1.8 & & \\
\hline & Above & 3 & 2.8 & 4 & 3.8 & 2 & 1.8 & & \\
\hline \multirow{2}{*}{ ATSC } & Yes & 28 & 26.4 & 35 & 33 & 11 & 10.4 & 0.005 & $0.946 \mathrm{NS}$ \\
\hline & No & 12 & 11.3 & 15 & 14.2 & 5 & 4.7 & & \\
\hline \multirow{4}{*}{ SRBMPPC } & Very good & 0 & 0 & 8 & 7.5 & 5 & 4.7 & 5.310 & $0.025^{* *}$ \\
\hline & Good & 5 & 4.7 & 5 & 4.7 & 2 & 1.8 & & \\
\hline & Satisfactory & 19 & 18 & 15 & 14.2 & 4 & 3.8 & & \\
\hline & Poor & 16 & 15 & 22 & 20.8 & 5 & 4.7 & & \\
\hline \multirow{2}{*}{ PTAA CC } & Yes & 19 & 18 & 28 & 26.4 & 12 & 11.3 & 3.034 & $0.084^{*}$ \\
\hline & No & 21 & 19.8 & 22 & 20.8 & 4 & 3.8 & & \\
\hline \multirow{2}{*}{ РPOMPPC } & Yes & 9 & 8.5 & 16 & 15 & 8 & 7.5 & 3.734 & $0.054^{*}$ \\
\hline & No & 31 & 29.2 & 34 & 32 & 8 & 7.5 & & \\
\hline \multirow{2}{*}{ PCHOCDMP } & Yes & 9 & 8.5 & 16 & 15 & 8 & 7.5 & 2.294 & $0.129 \mathrm{NS}$ \\
\hline & No & 20 & 18.7 & 15 & 14.2 & 6 & 5.7 & & \\
\hline
\end{tabular}

**, *Significant at $5 \%$ and $10 \%$ probability level, respectively (source: Model Output, 2020).

TABLE 14: Contingency coefficient for dummy/discrete variable.

\begin{tabular}{lcccccccc}
\hline No. & Variable & MSHH & EDUL & ATSC & SRBC & PTAACC & PPMPPC & PCHMPPC \\
\hline 1 & MSHH & 1 & -0.140 & -0.301 & -0.019 & 0.045 & 0.111 & 0.158 \\
2 & EDUL & & 1 & 0.215 & 0.087 & -0.011 & 0.032 \\
3 & ATSC & & & 1 & 0.520 & 0.075 & 0.131 \\
4 & SRBC & & & & 1 & 0.167 & 0.711 \\
5 & PTAACC & & & & & 1 & 0.067 \\
6 & PPMPPC & & & & & & & 0.181 \\
7 & PCHMPPC & & & & & & & -0.113 \\
\hline
\end{tabular}

Source: Model output (2020).

access to and utilization of agricultural inputs (ATUAGI), perceived satisfaction of the members with cooperative service (PMSTCS), education level of the household
(EDLHH), access to savings and credit service (ATSAC), services rendered by multipurpose primary cooperatives (SRBMPPCs), and perceived challenges of multipurpose 
TABLE 15: Result of ordered logit model regression.

\begin{tabular}{|c|c|c|c|c|c|}
\hline No. & Variables & Coefficient & Odds ratio & Std. error & Significance \\
\hline 1 & AGHH & 0.007 & 0.112 & 0.021 & $0.737 \mathrm{NS}$ \\
\hline 2 & FSHH & 0.72 & 4.974 & 0.323 & $0.026^{* *}$ \\
\hline 3 & TAIHH & 0.000 & 13.409 & 0.005 & $p \leq 0.001^{* * *}$ \\
\hline 4 & SHНAHН & 0.938 & 15.992 & 0.235 & $p \leq 0.001^{* * *}$ \\
\hline 5 & LHSHH & -0.527 & 1.676 & 0.407 & $0.195 \mathrm{NS}$ \\
\hline 6 & LSHSHH & -0.170 & 1.069 & 0.164 & $0.301 \mathrm{NS}$ \\
\hline 7 & DFCS & -0.973 & 6.853 & 0.372 & $0.009^{* * *}$ \\
\hline 8 & ATUAGI & -0.489 & 4.616 & 0.228 & $\mathbf{0 . 0 3 2}^{* *}$ \\
\hline 9 & PMSTCS & 0.662 & 9.148 & 0.219 & $0.002^{* * *}$ \\
\hline 10 & MSHH & 0.733 & 2.49 & 0.465 & $0.115 \mathrm{NS}$ \\
\hline 11 & EDULHH & 0.554 & 5.208 & 0.243 & $0.022^{* *}$ \\
\hline 12 & ATSC & -1.239 & 3.451 & 0.667 & $0.063^{*}$ \\
\hline 13 & SRBMPPC & 1.524 & 6.002 & 0.662 & $0.014^{* *}$ \\
\hline 14 & PTAACC & -0.310 & 0.399 & 0.499 & $0.528 \mathrm{NS}$ \\
\hline 15 & PPOMPPC & -0.566 & 0.321 & 0.999 & $0.571 \mathrm{NS}$ \\
\hline 16 & PCHODMP & 0.936 & 3.06 & 0.535 & 0.080* \\
\hline
\end{tabular}

${ }^{* * *},{ }^{* *},{ }^{*}$ Significant at $1 \%, 5 \%$, and $10 \%$ of probability level, respectively; NS = not significant; dependent variable: cooperative members' participation in activities of MPPCs; $-2 \log$ likelihood $=31.157$; chi-square $=208.335$; significance level $\left(p \leq 0.001^{* * *}\right)$ (source: Model Output (2020)).

primary cooperatives (PCHMPPCs) significantly influence the dependent variable.

Education level of household (EDLHH): education level of members is expected to influence the participation of members in activities related to cooperatives positively [31]. It was expected that when they are more educated, they are more aware of their duties and responsibilities, have accessibility to seek information, and quickly understand the benefits of collective efforts and the value of cooperation. Therefore, according to the model output of this study, education level has positively and significantly influenced the dependent variable at a 5\% probability level. Furthermore, when the impact of other variables is held constant, the result of the odds ratio favoring members' level of involvement grows by a unit of 5.208 as their level of education increases by one. The result of this finding is consistent with $[18,32]$, and a similar result was also found by Jemal [33], on the analysis of the role of cooperatives in agricultural input and output marketing in the eastern zone of the Tigray Region.

Family size of households (FSHHs): this is a continuous variable, and it was expected that a large family size might positively and significantly affect the dependent variable. Hence, the ordered logit model output value reveals that family sizes positively and significantly affect the dependent variable. On the other hand, the result of odds ratio in favor of the members' level of participation is also increased by 4.974 as their family size increases by one member in controlling the impacts of other variables constant. However, the findings of this study are not consistent with the result of Mengistu [19], which states that family size is negatively and insignificantly related to the participation of women in cooperative activities, and this result is also not in agreement with the study conducted on the performance of coffee marketing cooperatives and the satisfaction of the members $[34,35]$.

Total annual income of the household (TAIHH): in a given year, the total profits of cooperative members from additional income-generating schemes from on-farm and off-farm activities are calculated. One of the most important elements for cooperative members to expand their participation in various cooperative activities is their income. Members with a higher level of income from a variety of sources are expected to participate actively in the cooperative's many activities [36]. Members' paid-up share capital is what this term refers to. It was thought that the more shares a member has, the more involved they are in the cooperative and the more they benefit from the profit dividend generated by the cooperative's commercial activities in a given year. As a result, at a $1 \%$ probability level, the model output result demonstrates a positive and substantial association between Shareholding amount and members' degree of participation in their multipurpose primary cooperatives.

Shareholding amount of households (SHAHHs): members' paid-up share capital is what this term refers to. It was thought that the more shares a member has, the more involved they are in the cooperative and the more they benefit from the profit dividend generated by the cooperative's commercial activities in a given year. As a result, at a $1 \%$ probability level, the model output result demonstrates a positive and substantial association between shareholding amount and members' degree of participation in their multipurpose primary cooperatives. When the shareholding amount of a household increases while all other parameters remain fixed, the chances ratio in favor of the members' level of participation increases by 15.992 . Members in the study area owned more than one share, according to information obtained from focus group discussion (FGD) 
and key informant interviews (KIIs), even if the amount of capital they contributed to purchase the share was significantly less, because they expected some amount of profit dividend as part of the income-generating scheme. Findings of Gecho and Esayas were comparable [37].

Access to saving and credit services (ATSCs): membership in savings and credit services through cooperatives in terms of access and availability of money, production, and input. Access to saving and credit situations is critical for improving the use of input/ output service enrolment and is predicted to have a beneficial impact on members' level of engagement in a cooperative organization [29]. At a $10 \%$ probability level, the model output result demonstrates a negative and significant association between use and accessibility of saving and credit services with members' degree of participation. As a result, the chances ratio favoring members' participants decreases by 3.451 as their use and accessibility of saving and credit services increases. On the other hand, the results of the focus group discussions (FGDs) and key informant interviews (KIIs) conducted during the survey of this study revealed that there are no readily accessible credit and savings institutions that meet the needs and interests of the members. Mengistu [19] conducted a similar study, and her findings are in line with hers.

Distance from the cooperative service: the proximity of the cooperative institutions from the members' house reduces the cost of time and labor that the farmers spent searching for various services from MPPCs. The distance from the cooperative was expected to have a positive relationship and was expected to significantly influence the dependent variable. At a $1 \%$ probability level, the distance between the cooperative center and the respondent's residence was found to have a significant and negative link with the members' level of participation, according to the logit model results. The findings also show that the distance to the cooperative office has an inverse association with the likelihood of participation in an agricultural cooperative. This is justified because when the cooperative office is close to the household head, the farmer's time and effort spent communicating with cooperative officers is minimized. This study's findings were similar to those of Ahmed and Mesfin [38]. Farmers who live close to the cooperative headquarters will also have a better understanding of the cooperatives and their benefits. When the distance between cooperatives grows while all other factors remain constant, the chances ratio in favor of members participating in various cooperative activities decreases by 6.853 . This study's findings were similar to those of Daniel and Titman [39], Jemal [33], and Muthyalu [40], but Mengistu [19] conducted a similar study; however, the results were not significant for her dependent variable.

Access to and Use of Agricultural Inputs (ATUAGI): this is a continuous variable that relates to a member's ability to buy and use a certain volume of agricultural inputs. As a result, a positive and significant impact on the dependent variable was expected. At a 5\% probability level, the model output demonstrates a negative and significant link between agricultural input access and usage and members' participation in various activities of multipurpose primary cooperatives. As their access and utilization rate improves while other parameters remain constant, the value of the odds ratio in favor of members' engagement in multipurpose primary cooperatives decreases by a factor of 4.616 .

Services Rendered by Multipurpose Cooperatives (SRBMPCs): it refers to the capacity of multipurpose primary cooperatives to deliver scheduled activities to its members, as well as their dedication to providing efficient and effective services within a certain time and budget. The dependent variable was expected to have a positive and substantial association with it. As a result of the ordered logit model analysis, it appears that there is a positive and significant association between member participation levels at a 5\% significant level. As their service rendering capacity rises, the odds ratio in favor of members participating in multipurpose primary cooperative increases by a factor of 6.002 while all other parameters remain constant.

Perceived Challenges of Multipurpose Primary Cooperatives (PCMPPCs): this relates to members' perceptions of cooperative challenges, which prevents members from participating in various activities of multipurpose primary cooperatives. The dependent variables were predicted to have a significant and negative association. However, at a $10 \%$ likelihood level, it has a substantial and positive link with the members' level of involvement, according to the results of the ordered logit model. When controlling for the effects of other variables, the odds ratio in favor of the members' level of participation in multipurpose cooperatives improves by 3.060 as their assessment of cooperative challenges increases, controlling the impacts of other variable constant. During the focus group discussion (FGD) and key informant interview (KII) held during the survey for this study, it was clearly stated that MPPCs face a variety of socioeconomic, institutional, and psychological issues that can discourage members from participating in various cooperative activities.

Perceived member satisfaction with cooperative service (PMSTCS): it refers to the degree to which members have a positive or negative attitude about multipurpose primary cooperatives services. It could be a member's favorable or negative reaction to the frightening issues of multipurpose primary cooperatives in the study area, depending on the interview supplied to the respondents. As a result, it was predicted that it would have a positive or negative impact on the dependent variable. If respondents have a favorable or sympathetic opinion about cooperative services, the dependent variable is likely to be 
positively influenced. If individuals have a negative perception, it may have a negative impact on the dependent variable. As a result, at a 1\% level of probability, member satisfaction has a substantial effect and a positive link with members' level of participation in different cooperative activities, as evidenced by the ordered logit model output. When all other parameters are held equal, the chances ratio favoring members to engage in cooperatives increases by 9.148 for those who have a favorable impression of cooperative services. The conclusions of this study agree with those of Seifu [17] and Mengistu [19].

\subsection{Summary of Qualitative Data Analysis by Focus Group} Discussion and Key Informant Interview. Qualitative data were acquired from nonsampled respondents using checklists for focus group discussion (FGD) and key informant interview (KII), which had 10 and 12 members, respectively. Some pertinent information on the overview of multipurpose primary cooperatives in the study area was acquired from the following sources, and their perception was attempted to present as follows.

Cooperation and cooperatives have been found in studies to be effective and efficient in diminishing and eliminating economic unfairness and disparities among nations [41]. However, the importance of multipurpose primary cooperatives for social and economic development was not adequately considered and recognized by local governments and various stakeholders in the study region, according to the focus group discussants and interviewees in the study area.

According to the perceptions of focus group discussants and key informant interviewees, existing multipurpose primary cooperatives in the study area face a variety of economic and social issues, including poor member participation, low technical support and follow-up by concerned stakeholders, a lack of adequate capital and longterm credit to ensure cooperatives' investment in various projects, a lack of financial and economic strength among members, and a lack of adequate capital and long-term credit to ensure cooperatives' investment in various projects.

During the survey period, the focus group discussion (FGD) and key informant interview (KII) conducted at those three multipurpose primary cooperatives revealed that member participation is very low and poor in activities such as bylaw approval and amendments, annual planning and budget approval, and participation in evaluating cooperative activities. On the other hand, the participation of members in activities such as acquiring agricultural input, purchasing additional shares, and receiving profit dividends, on the other hand, is relatively high. Due to the constraints and gradual deterioration of members' participation in different activities of multipurpose primary cooperatives in the study area, the focus group discussants and KI interviewees emphasized that the multipurpose primary cooperatives have failed to achieve a sustainable performance. Discussion in Focus Groups and KI Interviewees were also asked to share their thoughts on the future viability of multipurpose primary cooperatives, which they believe is in jeopardy. As a result, it is vital to awaken cooperative promotion sectors at the grassroots level, including regional, zonal, district, and multipurpose primary cooperatives, as well as their personnel and stakeholders at all levels. As a result, the information gathered from the FGD and KII assisted in triangulating quantitative data results and determining the research's credibility. During the survey period, it was suggested that to improve the current worsening environment of multipurpose primary cooperatives, serious improvement measures should be taken widely for the sustainability and development of cooperative sectors, as well as for the social and economic development of the study area.

\section{Conclusions and Recommendation}

4.1. Conclusion. The development and progress of cooperative organizations are dependent on the active participation of their members. It is quite difficult to perform well, address, and meet the needs and requirements of members without active enrolment of members in various cooperative activities. On the other hand, if member engagement is very low or nonexistent, cooperatives may be unable to deliver efficient and effective services to their members. As a result, governments and policymakers, as well as other interested parties in cooperative organizations, should work to increase member participation in matters such as general meetings, voting and election, approval and amendment of bylaws, approval of annual planning and budget, participation in evaluating cooperative activities, and participation in supplying agricultural products to cooperative organizations. According to the findings, education level, family size, total annual income, shareholding amount, access to saving and credit, distance from the cooperative service center, access to and utilization of agricultural inputs, services rendered by MPPCs, perceived challenges of MPPCs that discourage membership, and perceived members satisfaction with cooperative services are the determinant factors that affect the level of membership participation.

Education level, family size, total annual income, shareholding amount, services provided by MPPCs, perceived problems of MPPCs, and perceived satisfaction with cooperative services had beneficial effects as a result of the aforementioned examples. Access to savings and credit, distance from the cooperative service center, and access to and use of agricultural inputs all have a detrimental impact on member engagement. Age, marital status, landholding size, livestock holding size, perceived transparency and accountability, and perceived progress of MPPCs, on the other hand, had no significant effect on the amount of members' participation in various multipurpose primary cooperation activities in the study area.

4.2. Recommendations. The following recommendations have been made as a result of the study's findings:

(i) The participation index output indicates that just $15.1 \%$ of respondents are enrolled in the highest participation category, implying that member 
participation in various MPPC activities is very low in the research area. As a result, cooperative development offices and stakeholders must empower cooperative members to organize, carry out, and evaluate cooperative activities. The most important factor in human development is the level of education. The result of the ordered logit model demonstrates that education can have a positive and considerable impact on the dependent variable. Members who are well educated are more aware of their roles and responsibilities and thus have greater democratic rights in cooperatives. As a result, supporting continual education and training programs is critical to increasing member engagement in MPPC activities.

(ii) One of the obstacles impeding member engagement in multipurpose cooperative is family size. Compared to a small family, a large family size was projected to have a negative impact on family income in a variety of ways and can lead to selfsufficiency. As a result, governmental intervention is required to support the topic of family planning among members and nonmembers of rural families in order to increase participation in MPPC.

(iii) One of the most important things determining a member's manner of life is income. The total annual income of the members has a positive and significant impact on the dependent variable, according to the findings. Encourage cooperative members to diversify their income through a variety of income-generating activities, both on- and off-the-farm, in order to sustain members' livelihoods and increase their level of participation in various MPPC activities.

(iv) Members' participation in various MPPC activities has also been positively and considerably influenced by the shareholding amount of respondents. As a result, enticing existing members to purchase an extra share and motivating new members to join the cooperative are two of the most crucial concerns to boost member engagement in MPPCs.

(v) Access to savings and credit services has a negative and statistically significant impact on the dependent variable. As a result, governments and nongovernmental organizations (NGOs) should be involved in establishing mechanisms to encourage members' saving and credit opportunities, so that MPPCs can give both long- and short-term credits to resource-poor MPPC members. As a result, providing the best possible opportunity for members to save and access credit according to their needs and requirements increases their degree of participation in cooperative activities.

(vi) The distance from the cooperative service center has a negative and significant impact on the dependent variable. As a result, the implication should be that the cooperative promotion sector and stakeholders should examine and prioritize adjacent sites/locations when forming new cooperative associations.

(vii) Another critical issue is access to and usage of agricultural inputs: members' ability and chance to acquire and obtain the necessary type and amount of agricultural inputs. The output of the ordered logit model suggests that this variable has a negative and significant influence on the dependent variable. As a result, multipurpose primary cooperatives and other stakeholders should endeavor to supply primary and enough agricultural input while taking into account members' time, capital, and wishes to raise their level of engagement in cooperative operations.

(viii) Services supplied by MPPCs refer to MPPCs' ability to provide effective and efficient services to their members at the desired and planned level. However, as a consequence of the ordered logit model analysis, the MPPCs in the research region were poor and performed below the desired level. Simultaneously, this variable has a favorable and considerable impact on members' degree of engagement in MPPCs. As a result, the cooperative, promotion sectors, and other stakeholders should promote multipurpose primary cooperatives in order to ensure their service delivery capacity by eliminating internal and external restrictions that may hamper their ability to supply services.

(ix) The perceived challenges of MPPCs that inhibit the participation of members in this study have a positive and substantial effect on the dependent variable. A lack of adequate capital, a lack of saving and credit, a lack of a competent and committed manager, BODs, and employees, corruption and misuse of cooperative resources, a lack of active participation of members, and a lack of technical support and follow-up are among the prominent challenges that may discourage members' level of participation in the study area. As a result, NGOs and NGOs, as well as other stakeholders concerned, should provide research-based technical assistance in designing and developing methods to strengthen MPPCs capital, facilitate savings and credit opportunities, promote training and education to managers, BODs, and employees, and increase membership participation through technical support and follow-up. Furthermore, the cost-effective exploitation of cooperative resources should be advocated as one of the possible implications.

(x) Perceived members' happiness with cooperative services is another essential criterion for determining a member's degree of engagement. As a result, for the designed negative and positive statements, the satisfaction rate indicators were calculated and totalled using 5-point Likert scale 
tools. According to the model analysis results, this variable has a positive and significant impact on the dependent variable. As a result, stakeholders and cooperative promotion sectors at the district, zonal, and regional levels should design and implement appropriate policy amendments for cooperatives at the grass-root level to properly promote their duties, responsibilities, and activities in order to improve member participation and scale up their satisfaction rate to a high level.

(xi) Cooperative trainings also play an important role in climate-smart practices. Trainings on climate-smart practices and good agricultural practices (GAPs) should remain an important part of ICP's interventions in the Study area. This will not only increase cooperative members' resilience to climate change, but will also improve the quality of agricultural products produced by cooperative members.

\section{Abbreviations}

ADLI: $\quad$ Agriculture development-led industrialization

ANOVA: Analysis of variance

BODs: $\quad$ Board of directors

CADU: Chilalo Agricultural Development Unit

CC: $\quad$ Contingency coefficient

DOOCD: District Office of Cooperative Development

EPRDF: Ethiopian People's Revolutionary Democratic Front

ETB: $\quad$ Ethiopian Birr

FAO: $\quad$ Food and Agriculture Organization

FEDOKKD: Finance and Economic Development of Kindo Koysha District

FEDRE: $\quad$ Federal Democratic Republic of Ethiopia

FGD: $\quad$ Focus group discussions

GOs: Governmental organizations

$\mathrm{HH}$ : Household headed

ICA: International Cooperative Alliance

ILO: International Labor Organization

KII: $\quad$ Key informant interviews

KKDOCD: Kindo Koysha District Office of Cooperative Development

MOFED: Ministry of Finance and Economic Development

MPPCs: Multipurpose primary cooperatives

NGOs: Nongovernmental Organizations

OLM: $\quad$ Ordered logit model

OOCD: $\quad$ Office of Cooperative Development

OOFED: Office of Finance and Economic Development

PI: $\quad$ Participation index

SACCOs: $\quad$ Savings and credit cooperatives

SIDA: Swedish International Development

Association

SNNPR: Southern Nations, Nationalities, and Peoples Region

SPSS: $\quad$ Social Sciences Statistical Packages

TLU: $\quad$ Tropical Livestock Unit

VIF: $\quad$ Variance inflation factor

WADU: Wolaita Agricultural Development Unit
WZOFED: Wolaita Zone Finance and Economic Development Department.

\section{Data Availability}

The data will be provided upon the request of the corresponding author.

\section{Consent}

Not applicable.

\section{Conflicts of Interest}

All authors declare that they have no conflicts of interest.

\section{References}

[1] International Cooperative Alliance (ICA), STATISTICAL information on Cooperative Movement, vol. 23, International Cooperative Alliance (ICA), Brussels, Belgium, 2010, http:// www.icacoop/satstical.htm.

[2] Mousaei and Arayesh, Factors Affecting the Participation of Agricultural Cooperatives' Members, Department of Agriculture, Faculty of Agricultural Extension and education, Ilam Branch, Islamic Azad University, Ilam, Iran, 2011.

[3] Kildbary, Factors Affecting the Participation of Agricultural Cooperatives' Members, Department of Agriculture, faculty of agricultural Extension and education, Ilam Branch, Islamic Azad University, Ilam, Iran, 2011.

[4] The Federal Cooperative Agency, Facts and Figures about SACCO', Annual Report of the Year 2004/05, The Federal Cooperative Agency, Addis Ababa, Ethiopia, 2005.

[5] Z. Ayalew, A Study on the Repayment of Farmers Multipurpose Cooperatives Agricultural Input Credit in Amhara, MSc thesis presented to School of Graduate Studies of Haramaya University, Dire Dawa, Ethiopia, 2005.

[6] G. T. Abate, G. N. Francesconi, and K. Getnet, "Impact of agricultural cooperatives on smallholders technical efficiency; evidence from Ethiopia," Analysis of public and Cooperative Economics, vol. 85, no. 2, pp. 1-30, 2014.

[7] M. Muthyalu, "The factors that influence the participation of cooperative members in the agricultural input and output," 2013.

[8] J. Moon, Reflection in Learning and Professional Development, Taylor \& Francis, London, UK, 2006.

[9] Wolaita Zone Finance and Economic Development Department, Annual Statistical Abstract Report of Geospatial and Data System Administrative Directorate, Wolaita Zone Finance and Economic Development Department, Ethiopia, 2018.

[10] Finance Economic Development Office, Kindo Koysha, 2019.

[11] Federal Cooperative Agency of Ethiopia, Five Year Development Plan, Addis Ababa, Ethiopia, Federal Cooperative Agency of Ethiopia, Addis Ababa, Ethiopia, 2005.

[12] Kindo Koysha District office of Cooperative Development, Annual Physical and Financial Audit Report Presented for Board of Directors, Managers and Other Stakeholders of Cooperatives in Kindo Koysha District, Kindo Koysha District office of Cooperative Development, Kindo Koysha, Ethiopia, 2018.

[13] T. Yamane, Statistics, an Introductory Analysis, Harper \& Row, New York, NY, USA, 2nd. edition, 1967. 
[14] T. F. Liao, "Interpreting probability models (logit, probit), stage university paper on qualitative application in social sciences," 1994.

[15] W. H. Green, Econometric Analysis, Prentice Hall Inc., Upper Saddle River, NJ, USA, 6th edition, 2008.

[16] R. A. Likert, "A technique measurement of attitude," American Psychologist, vol. 22, p. 140, 1932.

[17] T. Seifu, "Access to and utilization of family planning information among rural women," in Adama District, Oromia National Regional State, Ethiopiap. 153, M. Sc. Thesis, Haramaya University, Dire Dawa, Ethiopia, 2008.

[18] R. Hirpo, "Determinants of Rural women empowerment. The case of selp help development credit services," in Haramaya District, East Hararge Zone, Ethiopiap. 101, M. Sc.Thesis, Hramaya University, Dire Dawa, Ethiopia, 2010.

[19] K. Mengistu, "Women participation in rural cooperative," The Case of Burie Woreda, pp. 30-47, Amhara Region, West Gojam, Ethiopia, 2010.

[20] T. Bernard, A. S. Taffesse, and E. Gabre-Madhin, "Impact of cooperatives on smallholders' commercialization behavior: evidence from Ethiopia," Agricultural Economics, vol. 39, no. 2, pp. 147-161, 2008.

[21] T. Bernard and D. J. Spielman, "Reaching the rural poor through rural producer organizations? A study of agricultural marketing cooperatives in Ethiopia," Food Policy, vol. 34, no. 1, pp. 60-69, 2009.

[22] J. Ito, Z. Bao, and Q. Su, "Distributional effects of agricultural cooperatives in China: exclusion of smallholders and potential gains on participation," Food Policy, vol. 37, no. 6, pp. 700-709, 2012.

[23] D. Abebaw and M. G. Haile, "The impact of cooperatives on agricultural technology adoption: empirical evidence from Ethiopia," Food Policy, vol. 38, pp. 82-91, 2013.

[24] T. Bernard, G. T. Abate, and S. Lemma, Agricultural Cooperatives in Ethiopia: Results of the 2012 ATA Baseline Survey, International Food PolicyResearch Institute, Washington, DC, USA, 2013, http://citeseerx.ist.psu.edu/viewdoc/download? doi=10.1.1.352.7458\&rep=rep1\&type $=$ pdf.

[25] D. Mojo, C. Fischer, and T. Degefa, "Social and environmental impacts of agricultural cooperatives: evidence from Ethiopia," The International Journal of Sustainable Development and World Ecology, vol. 22, no. 5, pp. 388-400, 2015.

[26] R. Thorp, F. Stewart, and A. Heyer, "When and how far is group formation a route out of chronic poverty?" World Development, vol. 33, no. 6, pp. 907-920, 2005.

[27] G. N. Francesconi and N. Heerink, "Ethiopian agricultural cooperatives in an era of global commodity exchange: Does organisational form matter?" Journal of African Economies, vol. 20, no. 1, pp. 153-177, 2010.

[28] E. Verhofstadt and M. Maertens, "Can agricultural cooperatives reduce poverty? Heterogeneous impact of cooperative membership on farmers' welfare in Rwanda," Applied Economic Perspectives and Policy, vol. 37, no. 1, pp. 86-106, 2014.

[29] SIDA (Swedish International Development Agency), Making Financial Market Work for the Poor Guidelines on Cooperative Micro Finance, SIDA (Swedish International Development Agency), Stockholm, Sweden, 2004.

[30] D. N. Gujarati, Basic Econometrics, McGraw-Hill/Irwin, New York, NY, USA, 4th edition, 2004.

[31] S. Parveen and I. Leonhäuser, "Empowerment of rural women in Bangladesh: A household level analysis," in Proceedings of the Conference on Rural Poverty Reduction through Research for Development and Transformation, October 2004, Berlin,
Germany, pp. 1-10, http://www.tropentag.de/2004/abstracts/ full/382.pdf.

[32] M. Argaw, "Determinants of members participation in primary multi-purpose farmers cooperatives in lay Armachiho District, North Gondar Zone, Ethiopia," 2018.

[33] M. Jemal, "Analysis of role of cooperatives in agricultural input and output marketing in the case of Eastern Zone of Tigray Ethiopia," MSc. thesis, Mekelle University, Mek'ele, Ethiopia, 2008.

[34] D. Tilahun, "Performance of coffee marketing cooperatives and members satisfaction in Dale District: SNNPRS Southern," M.Sc. thesis, Haramaya University, Dire Dawa, Ethiopia, 2007.

[35] A. Adane, D. Melak, and W. Mekuria, "Determinants to performance of multipurpose agricultural cooperatives (MPACs): a case of gondar zuria district, north Gondar, Ethiopia," International Journal of Economic Behavior and Organization, vol. 8, no. 2, pp. 23-30, 2020.

[36] V. Duy, "Determinants of household access to formal credit in the rural areas of the Mekong Delta, Vietnam," MPRA Paper No. 38202, http://mpra.ub.uni-muenchen.de/38202/, 2012.

[37] Y. Gecho and B. Esayas, "Determinants of women participation in agricultural cooperative activities: the case of Sodo Zurya Woreda, Wolaita Zone, Southern Ethiopia," 2016.

[38] M. H. Ahmed and H. M. Mesfin, "The impact of agricultural cooperatives membership on the wellbeing of smallholder farmers: empirical evidence from eastern Ethiopia," Agricultural and Food Economics, vol. 5, no. 1, p. 6, 2017.

[39] K. Daniel and S. Titman, "Market reactions to tangible and intangible information," The Journal of Finance, vol. 61, no. 4, pp. 1605-1643, 2006.

[40] M. Muthyalu, "The factors that influence the participation of cooperative members in the agricultural input and output marketing-a case study of Adwa District, Ethiopia," Journal of Business Management \& Social Sciences Research, vol. 2, no. 4, pp. 121-130, 2013b.

[41] M. Naeeni, "Promoting cooperation and public participation," Proceedings of the Cooperatives, Employment and Development Conference, vol. II, pp. 453-455, Yazd University Publications, Yazd, Iran, 2005. 